\title{
Energy Use as a Consequence of Everyday Life
}

\author{
Mattias Hellgren
}

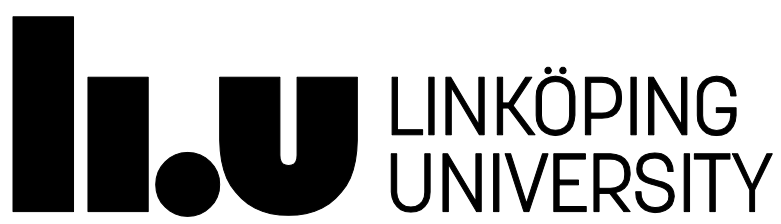

Linköping Studies in Arts and Science No. 662

Department of Thematic Studies - Technology and Social Change Linköping University

Linköping 2015 
Linköping Studies in Arts and Science • No. 662

At the Faculty of Arts and Science at Linköping University, research and doctoral studies are carried out within broad problem areas. Research is organized in interdisciplinary research environments and doctoral studies mainly in graduate schools. Jointly, they publish the series Linköping Studies in Arts and Science. This thesis comes from the Department of Thematic Studies - Technology and Social Change

Distributed by:

Department of Thematic Studies - Technology and Social Change Linköping University

SE-581 83 Linköping

Mattias Hellgren

Energy Use as a Consequence of Everyday Life

Edition 1:1

ISBN 978-91-7685-910-0

ISSN 0282-9800

(c) Mattias Hellgren

Department of Thematic Studies - Technology and Social Change

Printed in Sweden by LiU-Tryck, Linköping, Sweden, 2015 
This thesis is based on work conducted within the interdisciplinary graduate school Energy Systems. The national Energy Systems Programme aims at creating competence in solving complex energy problems by combining technical and social sciences. The research programme analyses processes for the conversion, transmission and utilisation of energy,

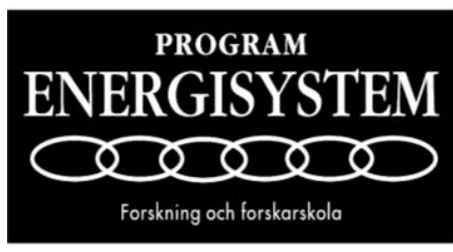
combined together in order to fulfil specific needs.

The research groups that constitute the Energy Systems Programme are the Department of Engineering Sciences at Uppsala University, the Division of Energy Systems at Linköping Institute of Technology, the Research Theme Technology and Social Change at Linköping University, the Division of Heat and Power Technology at Chalmers University of Technology in Göteborg as well as the Division of Energy Processes at the Royal Institute of Technology in Stockholm. Associated research groups are the Division of Environmental Systems Analysis at Chalmers University of Technology in Göteborg as well as the Division of Electric Power Systems at the Royal Institute of Technology in Stockholm.

www.liu.se/energi 


\section{CONTENTS}

ACKNOWLEDGMENTS $\quad$ i

1 INTRODUCTION 1

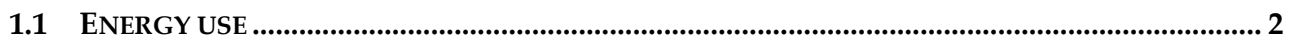

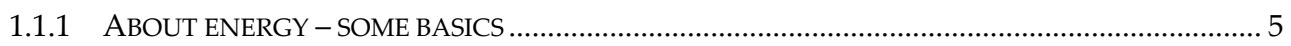

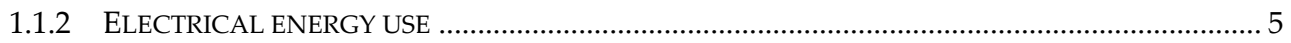

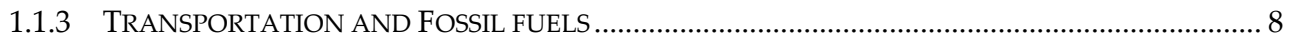

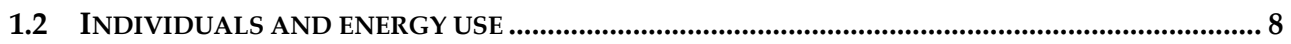

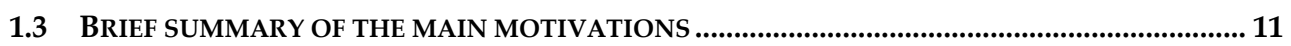

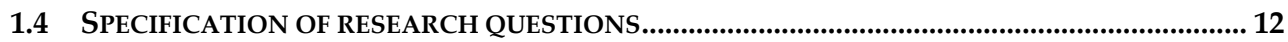

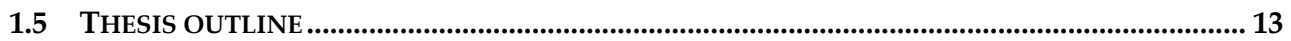

2 THEORETICAL GROUNDING

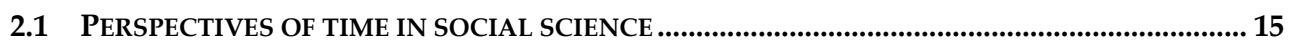

2.2 ASSUMPTIONS AND CONCEPTS IN THE TIME-GEOGRAPHIC APPROACH................................

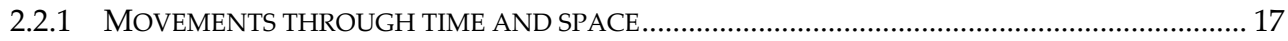

2.2.2 THE MOMENTS OF THE PATH - MOTIVATED BY PROJECTS AND ACTIVITIES ............................ 21

2.2.3 THE INDIVIDUAL PATH ON THE MOVE IN TIME-SPACE - PRISM AND POCKET OF LOCAL

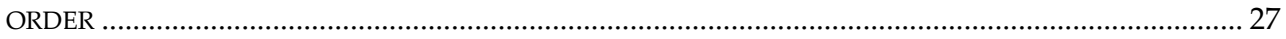

3 METHODOLOGICAL APPROACH 33

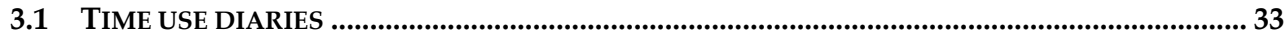

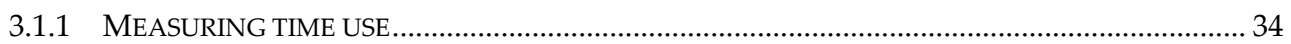

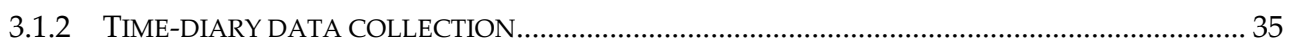

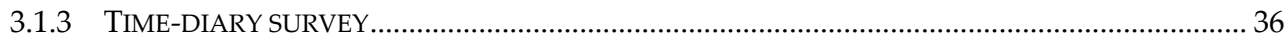

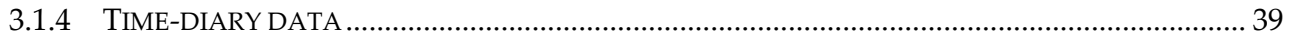

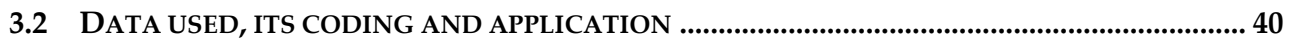

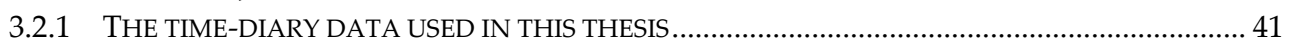

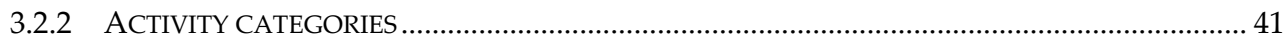

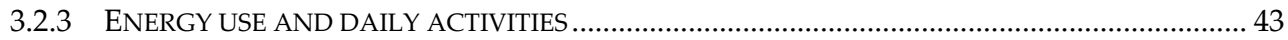




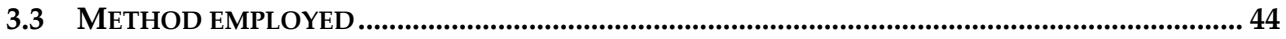

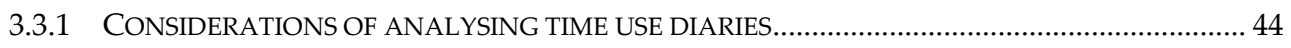

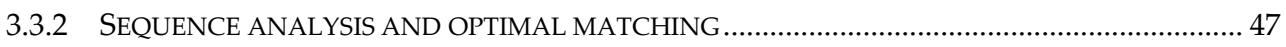

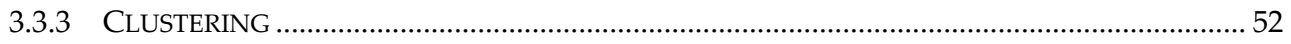

4 RESULTS

4.1 PAPER I: EXTRACTING MORE KNOWLEDGE FROM TIME DIARIES? .......................................56

4.2 PAPER II: THE IMPACT OF INDIVIDUAL ACTIVITY SEQUENCES ON ELECTRICAL ENERGY

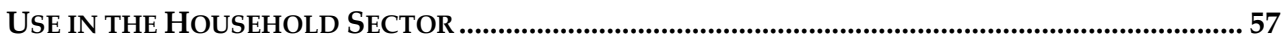

4.3 PAPer III: Deriving ENergy USe from the ConteXt OF PEOPle's EVERyday Life.... 58

4.4 PAPER IV: TIME FOR ChANGE? POTENTIAL FOR CHANGE AND CONSTRAINTS IN

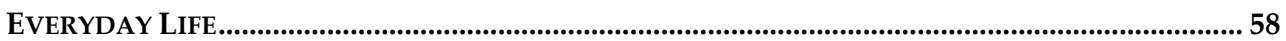

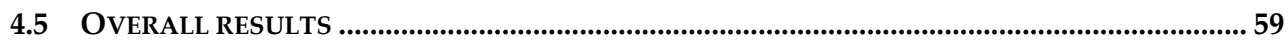

5 CONCLUDING DISCUSSION

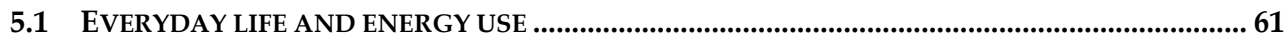

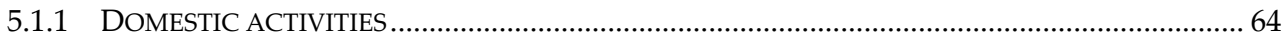

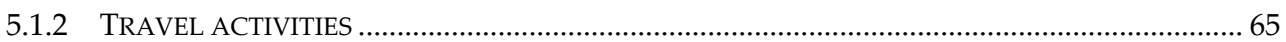

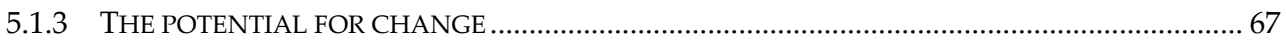

5.2 SEQUENCE ANALYSIS AND CLUSTERING AS A METHODOLOGICAL APPROACH ...................69

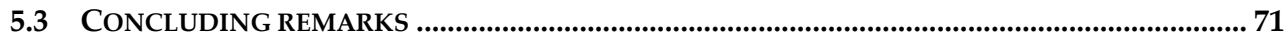

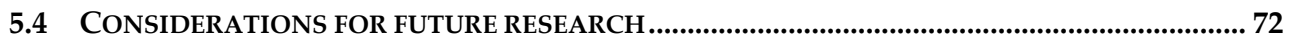

$\begin{array}{ll}6 \text { SUMMARY } & 75\end{array}$

$\begin{array}{ll}\text { REFERENCES } & 79\end{array}$

APPENDED PAPERS I-IV 


\section{LIST OF ILLUSTRATIONS}

\section{Figures}

Figure 1.1 Example of a load profile $\quad 7$

$\begin{array}{lll}\text { Figure 2.1 Individual path in time and space } & 18\end{array}$

$\begin{array}{lll}\text { Figure 2.2 Now-planes showing consequent moments } & 19\end{array}$

Figure 2.3 Project context for the project "having meals" 22

$\begin{array}{lll}\text { Figure 2.4 Everyday activity context } & 25\end{array}$

$\begin{array}{lll}\text { Figure 2.5 } & \text { Space-time prism } & 28\end{array}$

Figure 2.6 Pockets of local order $\quad 31$

$\begin{array}{lll}\text { Figure 3.1 Layout of a time-diary } & 38\end{array}$

Figure 3.2 Sequence of activities vs. collapsed activities $\quad 45$

Figure 3.3 Example of substitution matrix 51

Figure 3.4 Example of distance matrix $\quad 52$

\section{Tables}

Table 1.1 Final energy use in 2012 for Sweden and EU-28 4

Table 1.2 Final energy consumption in households by fuel for $2013 \quad 6$

Table 3.1 Example of time-diary data coded in SPELL format 40

Table 3.2 Main categories of HETUS and EGCS 42

Table 3.3 Activity electricity demand 43 



\section{LIST OF PAPERS}

I.

Hellgren, M. (2014) Extracting More Knowledge from Time Diaries?

Social Indicators Research 119:1517-1534

II.

Hellgren, M. The impact of individual activity sequences on electricity energy use in the household sector (submitted to Energy \& Buildings)

III.

Hellgren, M. Deriving energy use from the context of peoples' everyday lives a study of domestic and travel activities (manuscript, presented at the Association of American Geographers [AAG] Annual Meeting, Chicago, 2015)

\section{IV.}

Hellgren, M. Time for Change? Potential for Change and Constraints in Everyday Life (manuscript, presented at the 37th International Conference of International Association of Time Use Researchers [IATUR], Ankara, 2015) 



\section{ACKNOWLEDGMENTS}

The journey of a thousand miles begins with a single step.

Laozi

If a journey start with a single step it must also end with a single step. However in working on my thesis I have come to realise that the steps of the journey matters as much as where you start or where you end up. My journey as a PhD student has been my own, but I have not been alone.

My supervisor Kajsa Ellegård has been there from the beginning to the end, always showing support, keeping me from stumbling too much, helping me find my footing in the world of time-geography with great patience, and always having time for my worries. Thank you for your great care and supervision!

My assistant supervisor Tommy Svensson has always been there for me, ready to help me with whatever happened to be on my mind. Thank you for all the talks we have had throughout the years on theory, methodology, society, and human nature.

Before taking the first step of my PhD journey I took my first steps into the academic world at the Department of Sociology (Now the Division for Education and Sociology) where I was an undergrad, research assistant and teacher. To all great colleagues at the APS who have had the patience to work with me - Bo Davison, John Boman, Margareta Bredmar, Eva Ellström, Christer Johansson, Ulrik Lögdlund, Ann-Charlotte Münger, Peter Nilsson, Daniel Persson Thunqvist, Louise Svensson, and Linda Uhrbom - I'm in dept. A big thank you to the former, now retired, administrator Maude Tillfeldt who helped me get a grip on and navigate the university bureaucracy. 
My journey as a PhD student has been at a single place in space, at the Department of Thematic Studies - Technology and Social Change (Tema T). Here the seminar group Technology, Everyday Life, Society (TEVS) have been a warm and welcoming centre point in the weekly routines at Tema T. Here I have presented texts, been a part of a wonderful research group. I am grateful for all valuable comments throughout the years on texts I have presented. Who knows where this thesis would have been without your comments?

Katerina Vrotsou has help me wrap my head around sequences of activities, visualisation, and given me great help. Katerina has always been there for methodological discussions and to answer plenty of other questions I have had. Thank you for all your help and great discussions!

The journey of a PhD is in many ways like a roller-coaster, it goes up and it goes down. The group of PhD student I have had the pleasure to be a part of Réka Anderson, Maria Eidenskog, Linnea Eriksson, Linus Johansson Krafve, Lisa Lindén, Katharina Reindl, Hanna Sjögren, Josefine Thoreson and Anna Wallsten - have been there for support and company when the PhD rollercoaster have hit both highs and lows.

At Tema T our great administrator Eva Danielsson was constantly available for help and guidance in the PhD jungle. I am in debt to my Tema T colleague Lotta Björklund Larsen who allowed me to be the caretaker of "Pusser", an elderly lady cat, during her last years; a lady cat who tried to teach me that belly rubs are far more important than a silly thesis. Sleep well old lady.

My gratitude to Elin Wihlborg, Harald Rohracher, Peter Hedström, Maria Gustavsson, Jenny Palm and Ewa Väckelgård all who at my 60 and 90 per cent seminaries gave me valuable comments.

A special thank you to my colleague and friend Örjan Dahlström with whom I have had pleasant evenings discussing quantitate methods over a pint. Örjan, Tobias Lindberg and Mikael Heiman have through the years kept me running after a shuttlecock in my vain attempts to play badminton.

The compatriots of the good old "Flamman" gang Alexander Nordström, Pernilla Eliason, Mattias Gunnarson, Karin Gillenius, Jonas Nilsson, Helena Rosén, Tamara Yung, Lars Sandberg, and Eric Westas have always been there through the ordeals of life and held the traditions high. A special thanks to Eric for reminding me there is always time for a coffee and a chat. Thank you to Emil Linder, Mikael and Hjördis Farstrand, and Joel Paulsson for reminding me that there should be time for fun and games when working on a thesis.

During my PhD journey I have had the opportunity to collaborate and do coursework with Joakim Munkhammar and Pia Grahn. Thank you for good collaboration and fun times. 
I'm grateful for my sister Carina Rotegård and her husband, the best brother-in-law one could have, Rolf-Ingar. You are always welcoming and constantly try to have me come to visit you in the Norwegian mountains. While visiting my nieces Tuva and Hedda keep me alive with their antics, but rarely sane.

Lastly I would like to thank my Parents whom always have been supportive, considerate and encouraging. My mother Britt-Marie Hellgren have always believed in me, even when I have not believed in myself, and been a constant source of inspiration and joy.

My father Lennart Hellgren sadly passed away in the summer of 2015. I wish you could have seen the end of my journey. Without you as my parents I would never had taken this journey and I certainly would not been where I am today without your support and love.

Linköping, October 2015

Mattias Hellgren 



\section{1 \\ INTRODUCTION}

Global climate change poses many challenges for contemporary society. The UN conference in Rio in 1992 launched the idea of acting local and thinking global. This conveyed a message that urges individuals to change their daily behaviour in order to help saving our common environment. Later the message from the Intergovernmental Panel on Climate Change (IPCC) is that something has to be done to mitigate climate change. Both put to the fore the mundane daily life of individuals which relies heavily on utilisation of energy resources. A large part of the driving causes of global climate change lies energy generation (IPCC, 2013) with 87 per cent of all $\mathrm{CO}_{2}$ coming from fossil fuels, resulting in resulting in 31.7 billion tons of $\mathrm{CO}_{2}$ in 2012 (International Energy Agency 2014a). The thirteen remaining per cent are from land use, clearing of forests and industrial processes (Le Quéré et al. 2012).

Lowering energy use is a prime concern for the global community. The European Union have decided upon targets concerning climate change connected to energy use in the Europe 2020 goals - 20 per cent less greenhouse gases compared to 1990 level, 20 per cent more renewable energy and energy use should be 20 per cent more efficient by the year 2020 (European Commission, 2015). Conservation of and efficiency in the use of energy are important in order to meet the challenges of global climate change. This will have consequences for the whole of society.

In this thesis the focus will be on the individuals within society and their energy use in living their everyday life. Hence, structural factors such as infrastructure and energy taxation are not directly considered. For individuals there are two broad approaches to conserve and lower energy use: a technical and a behavioural (Poortinga et al. 2003, Semenza et al. 2008). The technical approach is generally an action performed at one instance, the investment in a more fuel efficient car or low energy refrigerator. This choice of technology 
will thereafter influence energy use for long. Behaviour concerns how the technology is utilised on a daily basis, and implies that consistently lowered energy use requires changes in the ongoing flow of everyday life. Behaviour is enacted in what activities individuals perform and the performances of activities in modern societies are commonly connected to the use of energy. For this reason the focus in this thesis will be narrowed down further to the activities that individuals perform in everyday life.

The aim of this thesis is to increase the knowledge about and common understanding of individuals' energy use as an outcome of their activities performed in everyday life. This is accomplished by exploring activities performed by individuals in everyday life and how individuals' sequences of activities affect energy use.

The aim will be framed in four research questions. However, before reaching these a brief excursion will be made into two areas of relevance for the motivation of the aim and research approach. The first (1.1) is brief backgrounds on energy use in general, the nature of energy and to explore the part that individuals in contemporary society play. While the specific technicalities of energy generation or consumption are not of relevance in themselves the consequences of them are. Specifically this is important for how electrical energy is consumed as there is a direct link between generation and consumption, which activities in everyday life is a part of. The motivations of focusing on individuals in everyday life are established in this section.

A second area of motivation is a brief assessment of how individuals relate to energy use (1.2). Here some notes will be made into arguments about individuals and their energy use that have inspired this thesis as well as how this relate to the approach in the thesis. The perspective on the individual will be further explored in the theoretical approach (Chapter 3).

Following this is a brief summary of the main motivations (1.3) which will more explicitly relate the two previous parts to the thesis. The chapter ends with the specific research questions (1.4) and an outline of the thesis (1.5).

\subsection{Energy use}

In order to frame the research aim there is a need to gain an overall understanding of the energy use, how the households and thus individuals living their daily life affect the overall energy use. Here the overall energy consumption will be presented and then narrowed down towards the use at individual level. 
In 2012 the global energy consumption was 39700 TWh (IEA, 2014b). This consumed energy comes from various sources such as water, nuclear and fossil fuels. As noted initially fossil fuels are strongly linked to global warming and environmental problems (IPCC, 2013) and in 2012 fossil fuels was the global source for 81.7 per cent of the energy produced (International Energy Agency 2015). Taken into account that fossil fuels are major contributors to greenhouse gases there is a link between energy use and the environment. For the year 2012 more than half (57.9\%) of greenhouse gas emission in EU-28 were from energy generation (European Environment Agency 2014).

Thus, there is a large interest to change energy generation from fossil based sources towards renewable, greenhouse gas free, sources such as photovoltaics and wind. The United Nations Framework Convention on Climate Change (UNFCCC) has seen a string of international negations and agreements, such as the Kyoto Protocol, to address this need to reduce emissions. The insight that reductions are need are evident in policy such the European Union's growth strategy EU 2020 and the more ambitious goals that can be found in the Roadmap 2050, where the goal is a reduction of greenhouse gases by 80 per cent by the year 2050 (European Climate Foundation, 2010).

So far there are two points to make: the first is that energy use is a major part of the environmental challenges facing contemporary society as energy generation is a major contributor to global warming. Secondly, that this is an important political issue where international, transnational, as well as national, regulations and treaties aim to lower emissions and mitigates environmental impacts. While the environmental impact can be mitigated by moving towards more sustainable sources of energy, as well as increasing the efficiency of the technologies that consume energy, there is also a growing realisation that this will in addition require behavioural changes (European Environment Agency [EEA], 2013). These behavioural changes imply that it is not only companies, organisations and governmental agencies that will have to change but also regular citizens - individuals - in their everyday lives.

With this in mind the question of how much of the energy is used by individuals becomes relevant. How big impact does the individuals in their everyday life have at aggregate level? Data from International Energy Agency (2012) show that globally 11 per cent of the final energy use in 2012 was used by the residential sector. Eurostat, the statistical office of the European Union, produces and reports the statistics on the final energy use in the EU-28, both overall and by nation. Eurostat report this in five economic sectors as displayed in Table 1.1; the table contains the values and proportions of this 
sectorial division of energy use for Sweden, as well as for comparison the energy use of EU-28 in 2012.

Table 1.1: Final energy use in 2012 for EU-28 and Sweden, 1000 tonnes of oil equivalent. Source Eurostat (2015a)

\begin{tabular}{lrrrr}
\hline & Sweden & \multicolumn{2}{c}{ EU-28 } \\
Sector & Energy use & $\%$ & Energy use & $\%$ \\
\hline Industry & 11669.4 & 36 & 282754.2 & 26 \\
Transportation & 8326.7 & 26 & 351717.7 & 32 \\
Residential & 7396.6 & 23 & 289150.5 & 26 \\
Agriculture/forestry & 439.3 & 1 & 23875.8 & 2 \\
Services & 4520.2 & 14 & 148687.7 & 14 \\
Other/Not specified & 0 & 0 & 7206.3 & 1 \\
\hline Total & 32375.8 & 100 & 1104480.0 & 100 \\
\hline
\end{tabular}

In Sweden industry is the largest sector in energy consumption, transportation is the second largest and the residential sector is the third. Compared to EU-28 where the transportation sector is the largest user of energy, the residential sector the second largest and industry is the third largest.

For individuals energy is used at home but also ought to include energy used for private as well as public transportation. Thus, the energy used by an individual in his or her everyday life is, in these statistical figures, divided between the transportation and residential sectors. While neither sector solely includes individuals' energy use it is relevant to note that the transportation and residential sectors together stand for close to 50 per cent of the total energy use in Sweden and almost 60 per cent in the EU-28. The two sectors are thus of great importance when it concerns the questions of how to reduce energy use and also make the energy use more efficient, both in Sweden and in the EU-28.

While the residential sector contains energy uses such as heating of buildings it also contains the energy use of individuals' use of appliances in their everyday activities. The end use electrical energy consumption in 2009 for appliances, lighting and cooking in dwellings was for Sweden 22 per cent, while for the EU-27 it was 19 per cent (European Environmental Agency, 2015a). It should be noted that the figures in the statistics concerning transportation includes the transport of goods as well as individuals. Of the energy used for transportation in EU-27 in 2011 the majority (51.6\%) was used by cars, motorbikes and busses making personal transportation a significant part of the energy use (European Environmental Agency, 2015b). Using a very 
rough and simple calculation ${ }^{1}$ it can be argued that roughly around 20 per cent of the final energy use in EU-27 comes from individuals' daily living.

\subsubsection{About energy - some basics}

All energy solutions operate on a simple premise: have energy bound within a source which then is released upon use. This can be done in multiple ways: by combustion, such as the use of petroleum, by chemical processes, such as batteries, and mechanically, capturing energy from wind and water, and nuclear, where sustained nuclear chain reactions are used.

There is a difference between the general use of electricity, which is commonly distributed via the electrical grid, and the direct use of fossil fuels (such as petroleum in a car bought from a gas station and stored in the tank of the car) lies in how the energy source is used and how the energy is transported. In direct use of fossil fuels the energy carrier (petroleum) is transported for use and the energy is released locally when the car is being used. The reversed is true for the general use of electrical energy. It is generated remotely from the point of use and it is the energy that is transported to the point of use. Essentially direct use of fossil fuels has the source of energy stored locally whereas the energy source used for electricity generation generally is remote.

The important point here is that in order to use energy the energy needs to be generated in the moment of its use. In particular this has consequences for electricity use as the demand of electrical energy is directly linked to its generation; if electricity demand goes up so must the generation. Failure to generate enough electricity according to demands means shortage (i.e. blackouts) and either restriction in use. Thus the when and how much electricity is used matters.

\subsubsection{Electrical energy use}

The everyday activities in the contemporary modern society are closely associated with the use of electricity as many appliances are utilised in daily life. The proportions of final energy consumption for households by fuel for the year 2013 are displayed in Table 1.2. In EU-28 nearly a quarter, 24 per cent, of the final energy consumption was electrical energy whereas for Sweden the same proportion was close to half, with 47 per cent.

Historically the high proportion of Sweden's electrical energy use can be traced to the abundance of hydro power and the expansion of nuclear power

\footnotetext{
${ }^{1}$ This is based on the contributions to energy use that is of appliances, lighting and cooking as well as cars, motorbikes and busses of the whole. This number should be treated as a very rough estimate.
} 
during the 70's and 80's (Swedish Energy Agency 2015a). In 2013 over 75 per cent of the electrical energy in Sweden was produced by hydro (37.6\%) and nuclear (39.2\%) sources (Statistics Sweden 2015a).

Table 1.2: Final energy consumption in households by fuel for 2013 (Eurostat 2015c)

\begin{tabular}{lrr}
\hline Final energy consumption & $\begin{array}{r}\text { Sweden } \\
(\%)\end{array}$ & $\begin{array}{c}\text { EU-28 } \\
(\%)\end{array}$ \\
\hline Petroleum products & 0.6 & 13.0 \\
Gas & 0.5 & 37.3 \\
Solid fuels & 0.0 & 3.4 \\
Electrical energy & 46.8 & 24.0 \\
Renewable energy & 14.5 & 14.6 \\
Derived heat & 37.6 & 7.6 \\
\hline Sum & 100.0 & 100.0 \\
\hline
\end{tabular}

While this describes the distribution of electrical energy use it does not relate to when energy is used. As noted earlier (1.1.1) when energy is used have a direct impact on variations in electricity demand over the year and the day. More electricity is used during winter then during summer times yielding sessional variations, more energy is demanded during daytime than during the night hours when a majority of the population is asleep yielding daily variations.

For the future of electricity generation there is a unique challenge in that modern renewable electricity resources, such as photovoltaics and wind power, differ from the more traditional sources of electricity, i.e. nuclear and hydro, used for energy generation, in that they are more dependent on factors outside human control; factor such as solar radiation and amount of wind. Therefore the energy generation from these sources have a more stochastic nature compared to the more traditional sources.

\section{Electrical energy demand}

Load profiles are a visualisation of the variation in electrical load over a specific time and they can be utilised to analyse the energy use. In Figure 1.1 an example of a load profile is given. This example is derived from the electrical energy use of activities during a day by one individual from the data material. On the $x$-axis the time of the day is visualised and on the $y$-axis the used effect; the higher the effect the higher the demand. From this example it is visible that the energy use is low during night hours (from midnight to 6 $\mathrm{am})$, being higher during the day and hitting a peak during the evening (6pm to $8 \mathrm{pm})$. 


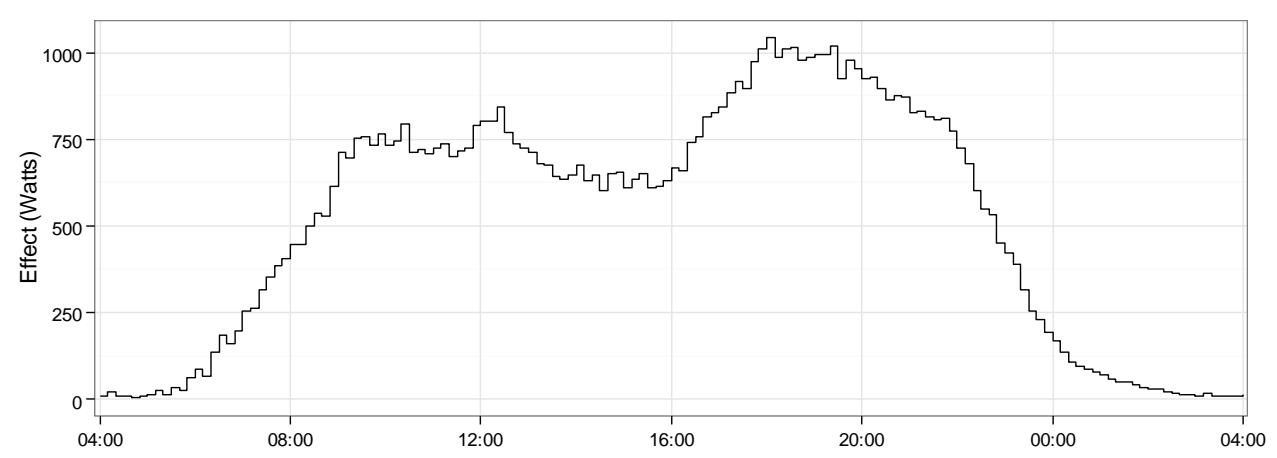

Figure 1.1: Example of load profile

In this example the demand of the individual is higher during the day and lower during the evening. By aggregating the energy demand of individuals, organisations and industries the grand total of energy demand during the specific times of the day can be calculated. While it is the aggregated demand which energy generation relates to, each individual's pattern of activities contribute to the total demand of electricity. When the demand is increasing the generation of energy must rise to match the demand. The timing of peaks and valleys thus has a direct effect on energy generation.

While the activities of an individual in their own right might have, compared to the whole, minuscule contributions to the demand it is the aggregate of all individuals in a region that is of relevance. Partly, the energy use of individuals in everyday life is rather static, such as heating and appliances such as refrigerators which can be addressed with in part with technical solutions. However other parts of the energy use depends on the activities of the individuals which claim electric appliances for their performance. A study conducted during the period 2005-2007 by the Swedish Energy Agency where electricity use at appliance level was measured for 400 households (Bennich 2007) show a large variation in energy use between comparable households, from 2000 to $7000 \mathrm{kWh} /$ year for detached houses and from 1000 to $5000 \mathrm{kWh} /$ year for apartments. This point towards something more than the technical side impact the electrical energy use. It also indicates that variations during the day depend on what, when and for how long individuals carry out energy consuming activities.

A concept that is gaining more ground in the discussion of domestic energy use is the smart control and the smart grid (Darby 2010; Strengers 2013; Nyborg 2015). Simplified smart control is a way to match the timing of the use of energy intensive appliances, in particular white goods such as dishwashers 
or washing machines, to the price or availability of electrical energy. The required information for this timing is signalled via the smart grid; essentially a regular electrical grid which have the additional capacity to carry information of price or availability.

While the smart grid and appliances is largely a technical discussion there is for this thesis a social component of relevance. The use of smart grids implies a change in when appliances are used. Thus the use of smart grids would require changes in user behaviours, thereby affect how they structure the activities of their everyday life.

\subsubsection{Transportation and Fossil fuels}

The by far most common source of energy for transportation is fossil fuels. According to data from Eurostat (2015b) the share of energy from renewable sources in transport for the year 2012 was 16.7 per cent for Sweden and 5.4 per cent for EU-28. As noted earlier the direct use of fossils fuels differ from electrical energy in that the energy is generated from the fuel while driving. The effect of this is that the exact timing is not as important for the energy use, rather how much is consumed over a period of time. However it is still by performing transportation activities that individuals use energy.

A minor note for the future is the advent of electrical vehicles. With an increase in electrical vehicle there is a potential for shifting the energy demand from fossil fuels to the electrical grid and batteries for temporal storage of the energy. When the fleet of electrical vehicles is large, the cars will be large consumers of energy and the timing of when they are being loaded which will have an impact on the electricity demand.

\subsection{Individuals and energy use}

As noted initially there are, broadly speaking, two different aspects of the individuals' energy use, a technical and a behavioural (Poortinga et al. 2003; Semenza et al. 2008). The technical is tied to the material aspect of energy use, such as buildings, apparatus, appliances and vehicles, which consume energy when utilised by individuals. The behavioural aspect concerns how these materials are being used. In order to affect the energy use towards lower levels there is a multitude of pathways.

For the buildings in which individuals have their homes, technological efforts can be made to lower the demand for heating or cooling by insulation. Behaviourally changes in comforts, such as lowering indoor temperature during winter time can achieve similar results, or even greater results when in conjuncture with technological changes. The user of energy, the individual, 
can be approach from multiple angles in order to encourage energy conservation. Common approaches depart from the link between behaviours and attitudes, or economic rationality. Here, however, three other approaches will be explored, which take not only the individual but also the social and material contexts into account. While there are several approaches ${ }^{2}$ here a selected a few examples, that by the author been found to be nuanced and inclusive, have been chosen.

Aune (1998) wove the social, material and cultural aspects of energy use in households together and studied differences among households in their using and thinking about energy. A conclusion drawn was that that individuals' relation to and use of their home affected their energy use. Aune (2007) identified three categories of ideas that households' held about the home: the home as haven, as project and as an arena for activities. She claimed that an economic rational view of people's energy use does not correspond to the complexity of people's everyday life. She underlines the importance of investigating everyday life as a whole.

Shove $(2003,2004)$ takes a point of departure in how expectations of comfort, cleanliness and convenience have radically changed and how these changes impact on the perception of what is seen as normal. In exploring how energy is used in social practices Shove argues that the normalisation of comfort, cleanliness and convenience have led to standards of living. An example brought up is that of air-conditioning. With the ability to set the temperature, a specific temperature becomes the norm and activities in the household are based on these assumptions.

Shove argues that much of the environmentally significant consumption in everyday life is invisible as it is part of routines and habits. In order to affect energy use Shove argues that the ideas of comfort, cleanliness and convenience needs to be taken into account. Her focus is upon the practices in the household and not the activities themselves. Attitudes and perceptions of comfort, cleanliness and convenience are important but they lack the actual actions taken by the individuals. Shoves aim is however not to challenge that the importance of what is done, but rather to put into question the notion that a wider adoption of a "green lifestyle" is to be gained from disseminating 'green' beliefs. Arguably the main interest of individuals is the services and comfort their energy consumption may result in (Shove 2003; Lindén \& Carlsson Kanyama 2007).

\footnotetext{
2 See for example Berker 2013, Palm \& Darby 2014, Powells et al. 2014, Strengers 2013, Strengers et al. 2014; Wallenborn \& Wilhite 2014.
} 
Gram-Hansen showed that what individuals regard as comfortable indoor climate varies between householders and that difference in income is an important factor explaining why households of the same size consume different amounts of energy (Gram-Hansen 2003, 2008). Druckman \& Jackson (2008) identify a strong relation between income and household energy use. They add other important factors influencing energy use, namely type of dwelling, tenure, household composition and geographical location.

Spaargaren (2003) argues for a more inclusive model by taking a point of departure in the structuration theory of Gidden's $(1984,1991)$ human agency and social structure. The suggested model implies the end of the individual as the central unit of analysis where human agency is analysed not in terms of the isolated individual rather in terms of the concepts of lifestyles and social practices.

From this model it is argued that daily routines like food, travel, and leisure have to be taken as a starting point for policymaking. The aim of policy making needs to be specified from a life-world perspective of the individuals in order to be recognised and have concrete effects on their lifestyles. This is put forward as a critique of policy framework where the aims are formulated in a technical language. Further, Spaargaren (2003) lifts forward the issue of social change in regards environmental issues and the tendency to individualise the responsibility for the realisation of the goals to reduce energy use. Spaargaren (2003) presents as a counterargument to the individualisation of responsibility that the responsibility of the individual should be analyse in direct relation with social structure.

Skill $(2008,2012)$ uses the term "ecological action space" to discuss green activities and how they can be reached. Having roots in the time-geographic approach this concept takes its point of departure in that individuals can only be understood in relation to the system and structures surrounding him or her. A point here is that the structures are simultaneously created and recreated by the individuals through activities in their everyday life. What they do, how they go about doing it, why they are doing it and where they are while doing it is of importance. This perspective puts the emphasis on activities and the context in which they are performed. The encounter between the actor and the structure is central in the concept ecological action space as the structures are simultaneously created and recreated through individuals' praxis, and it is within these practices that energy is used.

A common theme in these approaches is a critique of the conceptualisation of the energy user as an autonomous individual in control, a critique that the author of this thesis shares. A piece of this puzzle that this thesis aims to 
explore is how the structure of the activities - what activity is performed, when and for how long - of everyday life affects energy use.

\subsection{Brief summary of the main motivations}

The energy use is a substantial part of the environmental challenges of contemporary society and as shown above (1.1) individuals living their everyday life are a significant part of this. The timing of energy use also matters. In the discussion on Electrical energy demand (1.1.2) the argument has been made that the timing of the use of electrical energy matters and that this timing is connected to what activities individuals' perform. Energy use for transportation is also related to the activities performed by individuals as the activity of transportation connects the various locations they visit in performing various activities during everyday life.

Activities in daily life are to an extent performed on routine and without deeper reflection. Consequently, getting reliable data on when and for how long activities are performed in everyday life is generally problematic. In order to handle this problem this thesis will rely on data from time use diaries. The character of time use diaries is explored in Chapter 3, however at the moment it is relevant to note that time use diaries contain little to no information about the individuals' motivations, expectations, attitudes, lifestyles choices or the social context they find themselves within, issues brought up as relevant and of importance in the discussion on perspectives of individuals and energy use (1.2).

It does however contain what activities are performed, when they are performed and for how long. It is here argued that time use diaries contains the manifestation of the motivations, expectations, attitudes, and lifestyles choices of individuals, and the social contexts of everyday life in the form of the activities individuals perform in order to fulfil motivations and expectations, handle the constraints and possibilities of lifestyles choices, social contexts as well as their attitudes. It should be noted that these manifestations also depend on the structures in society that constrain the individuals' performance of activities.

While a direct connection from the empirical material to individuals' as "living breathing human beings" cannot be made, a connection to how the activities of their everyday life are stringed together to a sequence of activities can. In approaching energy use from these sequences of activities an important dimension that seldom is covered in studies of energy use in social science can be made visible, namely the timing and the sequential order of the activities 
performed. Since the revealed sequence is performed it can be assumed that the activities within the sequence have some meaning to the individual.

This give rise to an initially subtle change in perspective as the focus will shift from who the individuals are (background variables) towards what they do (activity sequences performed). In a sense there will be an inversion of more traditional approaches where the background variables of the individuals are related to energy using activities. Here the sequences of activities will be in the forefront and the background variables afterwards will be related to the sequences of activities.

Hence, the assumption is made that what individuals do is a manifestation of their desires, goals, intents and hopes as well as expectation from others both in the sense of social norms and values and from individuals they relate to in their daily life. In pursuit of these they perform activities, activities which use energy. In exploring how the activities of everyday life are stringed together in sequences of activities this manifestation can be made visible. These sequences are constrained but also made possible by the social context and material world they find themselves within.

Another assumption made in this thesis is that while each individual's daily life, and thus sequence of activities, is unique there are commonalities to be found in how activity sequences are structured. By grouping (clustering) individuals with similar activity sequences together into aggregate activity patterns a more generalised picture can be identified. None of these aggregated activity patterns will be exact representations of everyday lives. Rather they can be seen as "typical", "average" or "common" which capture the general essence of the sequences. These aggregate activity patterns can then be used to explore how different sequences of daily life affect energy use.

\subsection{Specification of research questions}

The aim is to increase the knowledge about, and common understanding of, individuals' energy use as an outcome of their activities performed in everyday life. This aim is approached by exploring what activities individuals perform in everyday life, when they perform the activities, and for how long the activities are performed. The activities of everyday life are regarded as stringed together in sequences that affect their energy use.

As the approach in this thesis is to use the sequences of activities as the main empirical material rather than the more traditional method of relying on background variables when analysing the activities performed, there is a question of what this approach yields other than the traditional approach. It is from this consideration that the first research question springs: 
1. How can individuals' activity sequences from time-diaries on an aggregated level be used to explore everyday life that gives more knowledge than studies not taking the sequence into consideration?

The results from this first question will be discussed in detail later (4.1), and is covered in Paper I. Here, however, it is enough to say the method is promising and the results lead to the second and third research questions. In these two different perspectives were applied to energy use. In the second research question the energy use of aggregate activity patterns were analysed from the activities performed in the home, whereas the third research question departures in aggregate activity patterns of transportation and related this to the energy use of transportation as well as activities in the home. More specifically the second and third research question are:

2. What aggregate activity patterns can be identified from time-diaries for domestic activities and what domestic energy use can be derived from the activity patterns?

3. By exploring travel activities, what aggregate activity patterns can be identified and what is the combined energy use from transportation and domestic activities in daily life?

As noted earlier (1.1) part of obtaining sustainable energy consumption requires behavioural change. The previous research questions have focused on aggregate activity patterns related to energy use but not to the potential for changing these. By taking analysing everyday life and its energy use from the perspective sequences of activities a lingering question here is: What are the realistic opportunities for people to make changes in their activity sequences? This leads to the fourth and final research question:

4. By taking a time-geographic approach and using sequences of activities to explore how changeable individual's everyday life is: What are the realistic opportunities for people to make changes in their everyday life?

\subsection{Thesis outline}

This first chapter of the thesis has presented the motivations for the research as well as the research aim and research question. It has touched upon energy use, the environmental impact it has and why individual energy use is of relevance. 
The second chapter will present the theoretical grounding for the thesis. This thesis has a basis in the time-geographic framework and in this chapter the theoretical concepts that the thesis is grounded in are presented.

This thesis uses time-use diaries as its data material and methodologies to analyse sequences of activities. Considerations of analysing time use, the data material, and the applied methods - sequence analysis and clustering - are presented in the third chapter.

The fourth chapter will briefly present the results of the papers included in the thesis as well as some general findings and the fifth chapter will discuss and present the conclusions of the thesis and relate back to the aim and research questions.

The sixth and last chapter gives a brief overview of the thesis and summarise the main findings and conclusions. 


\section{2 \\ THEORETICAL GROUNDING}

This chapter will give the theoretical basis for the thesis. The focus is on individuals' energy use as an outcome of their activities performed throughout everyday life and thereby how the theoretical basis approaches time is crucial. The time-geographic approach is a theoretical grounding that regards activities performed as a continuous sequence of activities. This approach of exploring daily activities performed by individuals underlines their contextual links and here it will be used to explore how the individuals' daily sequence of activities affects their energy use.

This chapter will start with a brief overview of perspectives of time in social science as the views on time use that springs from these has an effect on how time is handled. Following this the time-geographic approach and relevant concepts will be presented.

\subsection{Perspectives of time in social science}

The focus of this thesis is not on peoples' experiences time but rather how their time is used. While there is research on the subjective experience of time within fields such as psychology and neuroscience, how the relationship between perceived and measured time functions, and how the individual's memories of past events are formed, this research focuses on the perceptions of time rather than what occurs in time.

Sociologist and social theorists have put considerable effort into understanding what is regarded as an increased pace of social life in modern societies. Harvey (1990) discusses this in terms of time-space compression where modern inventions are said to radically shorten or even eliminate spatial and temporal distances. Castells (2000) explores this notion by using the perspective of timeless space whereas Urry (2000) uses the term 
instantaneous time. Wajcman (2008) argues that the discussion on time pressure fails to take into consideration that the perception that life has become more rushed is due to increases in the combined work commitments of family members the household as a whole. While this research closes in on events in time; time is largely regarded as a resource that has become scarcer in modern societies rather than exploring how the patterns everyday life activities are formed.

Giddens (1979) notes that time-space relations are inherent in the constitution of all social interactions, a thought later developed in the book The Constitution of Society (Giddens 1986). There are clear influences by the time-geographic approach of the Swedish geographer Torsten Hägerstrand from which Giddens formulates an approach where social institutions act as stations that binds time and space for generations of actors. On an individual level routinisation and habituation form the stations for individuals in their everyday life. While Giddens take the consistency of everyday life into account and highlights the importance of routines and habits parts of the timegeographic approach are not considered.

The time-geographic approach puts to the fore the contextual importance of the activity sequences and how activities together form the everyday life. Time-geography offers a perspective on time which takes its point of departure in the individual's actions through space and time. This also is the intention of this in this thesis and therefore the theoretical grounding will be within the time-geographic approach.

\subsection{Assumptions and concepts in the time-geographic approach}

The time-geographic approach began its developments in the 1960's at Lund University, Sweden, by Torsten Hägerstrand and his associates. While the foundations were established in earlier work it was in the article "What about people in regional science?" Hägerstrand (1970) first presented the basic timegeographic concepts: individual path, indivisibility, constraints and projects for an international audience. In the following decades the approach was expanded and deepen by both Hägerstrand and others; concepts such as prisms, the principle of return, everyday life contexts have been introduced.

The time-geographic approach is based on the socio-material environmental structure, in which individuals exist and where they are influenced by structural limitations and constraints. By capturing interactions and movements at the individual level, limitations that are caused by the 
boundaries of time and space can be understood. Here, basic time geographic concepts (bold in the text) will be presented in a way that underlines how they are interlinked.

\subsubsection{Movements through time and space}

At the core of the time-geographic approach is time and space. A central insight is that all that occurs, occurs in time and space which implies that all actions and events that makes up a human individual's existence occurs as a sequence of activities in time and space. The smallest unit that can exist is the individual $^{3}$. An individual cannot be divided, it cannot exist in multiple locations at the same time nor can it occupy the same point in time-space as other individuals, Individuals rather exists side by side (Hägerstrand 1970, 1985, 2009). A consequence, the individual existence can be described as a continuous path through time-space and the time-geographic concept for this is the individual path (Hägerstrand 1970).

\section{The individual path}

In the time-geographic approach the individual path ${ }^{4}$ illustrates an individuals' continuous temporal sequence of activities in geographical space. This individual path is a fundament of the notation system of time-geography (Hägerstrand 1970, 1982; Lenntorp 1976, 1999) and it was early used to visualise the movements of individuals in time and space both in abstract terms and in empirical studies (see for example Hägerstrand 1985; Carlstein 1980).

The visualisation and use of individual paths have been, and is, successfully used in for example transportation research (e.g. Miller 2004; Vilhelmson 1999, 2007; Shaw 2006; Chen et al. 2011) and exploring the consequences of ICT (e.g. Harvey \& MacNab 2000; Kwan 2001; Shaw \& Yu 2009).

Figure 2.1 gives an example of how an individual's movements in the timespace is visualised. The path is formed by the activities taken by the individual, in the examples here by the individual "John". The individual path illustrates when John moves in time and space: Initially John was at home, after a while he left the home and travelled to a shop. After having spent some time shopping John continued onwards to a friend's place, where he remained

\footnotetext{
${ }^{3}$ In several time-geographic articles by Hägerstrand the individual was regarded as something abstract. He meant that the concept "individual" can refer to any indivisible object, artefact or person such as a chair, a stone or a human being (see for example Hägerstrand 2009). In this thesis the concept individual is only used for human beings.

${ }^{4}$ The individual path is also referred to as a space-time path, in the later work of Hägerstrand the term trajectory was used. In this thesis the term individual path will be used.
} 
for a longer period of time, at least until the visualisation ends. The bottom white area is a two-dimensional representation of geographical space (i.e. a map), whereas the third (vertical) dimension represents time. The black line is the visualisation of the individual path, whereas the grey line displays the movements in geographical space and the dotted vertical grey lines helps the reader to connect the individual path to the geographical space.

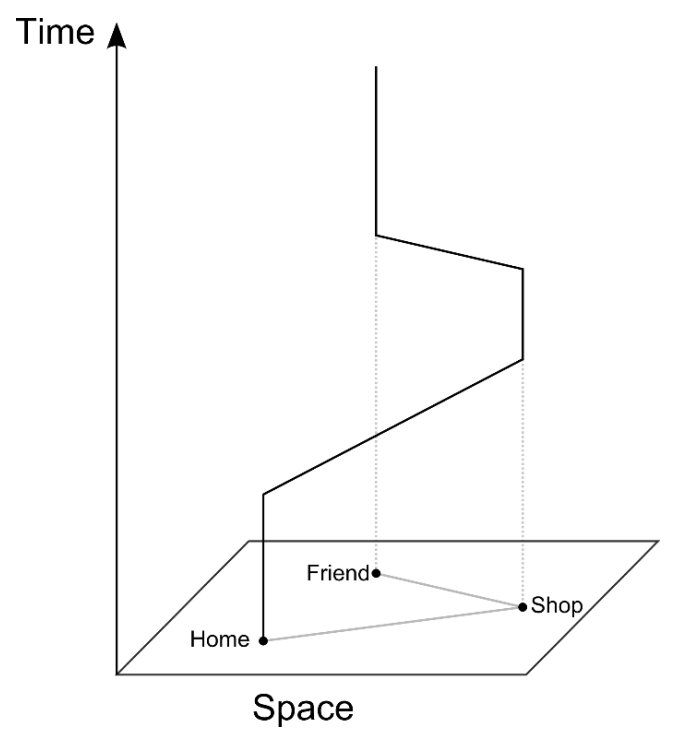

Figure 2.1: An individual path in time and space. The bottom area represents geographical space and the vertical axis represents time. Time should be read from below and upwards. Note that the stays at different places take time.

From an energy use perspective the path can be used to contextualise the individuals' movement in space and time. Where an individual is located geographically and what he or she does affect in many ways the energy use and the timing thereof. Since this thesis concerns what individuals do at various places, the individual path in its fundamental time-space shape will not be used, however it is a core fundament of the time-geographic approach.

Each moment in time can be described as a "now-plane" (or a now-line) where the individual always is positioned, but never can pass since the nowplane constantly moves ahead the path in time-space (Hägerstrand 1982; Lenntorp 1976). In Figure 2.2 the movement of the now-plane is exemplified at four different moments along the time dimension. The path that sequentially is formed between each moment is the same as the individual path of John in the example above. 

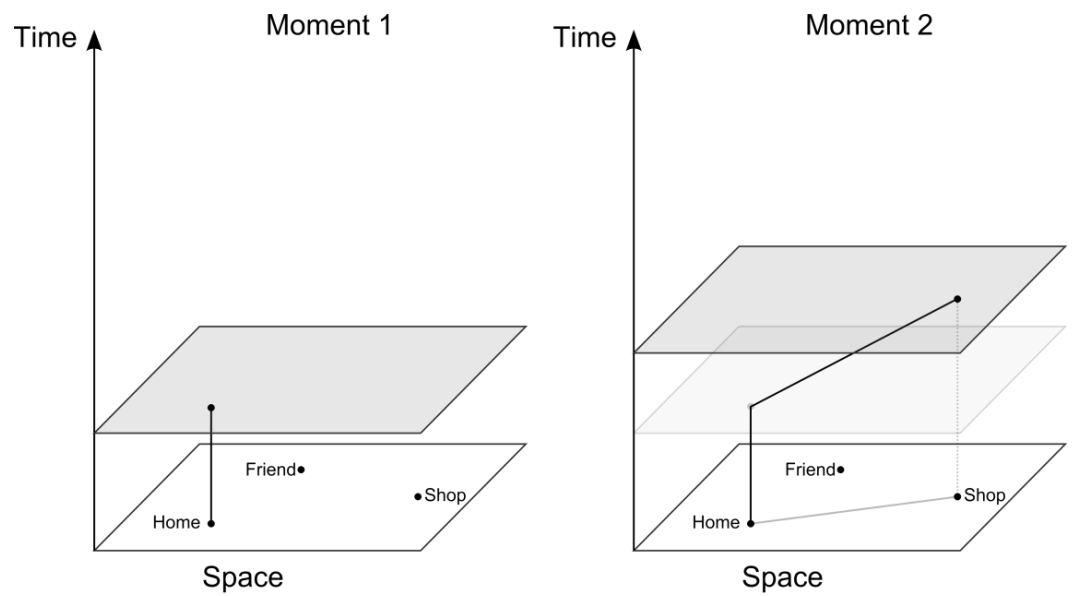

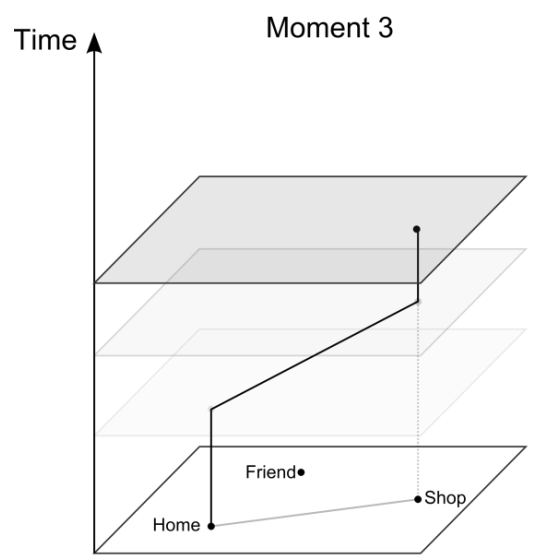

Space

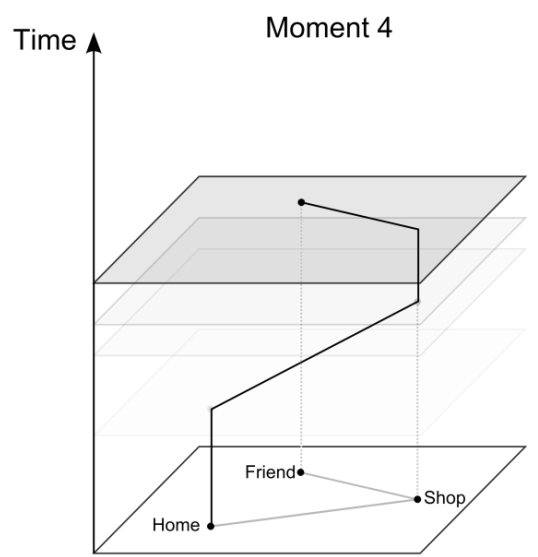

Space

Figure 2.2: Now-planes showing the consequent movements of a person illustrated by an individual path at time three moments forming the individual path presented in figure 1 (furthest right)

At the first moment the individual path (black line) below the now-plane (grey area) shows where John has been located in the past. This concerns the activities that he performed in his home. At the end of the first moment he is still in his home. Where the individual path may go in the future (above the now-plane) is at this moment still to a varying extent malleable, depending on his recourses. John could change his mind and remain at the home, he could travel directly to visit his friend or he could go to another location.

The now-plane moves upwards along the time-axis, as time passes between the first and second moment. During the time between the first and second moment John has moved in space, he has travelled from his home to a shop. In this second moment the travel activity has furthered the path in both time and 
space and john is now geographically located in the shop. The change in the geographical plane is illustrated by a grey line and the connection to the where the individual path is located in time is illustrated by a dotted light grey surface illustrating where the now-plane was located at the first moment. At the third moment John has been in the shop for some time. It is indicated by the individual path being parallel to the time-axis, illustrating the passing of time but no movement in space. During this time John has still performed activities, most likely deciding what beverage and snacks to buy, he has stood in line and payed for his goods, but none of these activities are directly revealed by the individual path. Again his future path is yet to be formed from the now-plane. He can decide on taking several actions from here, such as continue his journey to his friend or to return home. He does however decide to travel onward to his friend and his movements in time and space between the third and fourth moment is shown. Finally, at the fourth moment he arrives at his friend's house.

From this example there are a few important points to make. The first one is that John's movements in time-space follows the continuous movements of the now-plane. Simultaneously, as the now-plane moves, other individuals and objects in this environment also move in time-space. Hence, the now-plane is not only a representation of where in time-space John starts his movements in order to move himself into the next moment in time-space, but it also represents the starting points of other objects and people in the world surrounding John.

The second point is that the individual path is formed by previous activities performed in time-space. As the now-plane moves the potentials for activities that the individual can perform changes. In the first moment, for example, John has multiple options to where his path could lead, but as the now-plane continuously moves on his individual path is formed. If he stays where he was the individual path still is located at the same geographical location, but it moves in time. If he decides to travel to another geographical location, the individual path turns in that direction in space and it also moves in time.

The third point is that there is no moment in time where John is absent and that he is always located at some geographical location. Then, as time passes the activities John performs at various places during a period of time, create a continuous indivisible string of activities that are dependent on the activities performed prior.

In this thesis the movements in space will not be used per se as the data lacks exact geographical locations. However the third point, that the individual path formed by activities performed sequentially is important. 
While in the analysis of sequences of activities the geographical context is lost, the activities performed by the individual is not. This sequence of activities can be treated as a path in its own right, an individual activity path. As noted earlier (1.3) it is in the performance of activities that individuals use energy and by exploring the sequences of activities the context wherein energy is used can be explored. In combination with the empirical material, this argument lies behind the choice of this thesis to use the individual activity path rather than the individual path.

\subsubsection{The moments of the path - motivated by projects and activities}

Each point of the individual path reflects a moment of the individual's life in time-space. Each moment of the individual path, then, is formed by the activities that the individual performs, one after the other, at various places as time goes by. What activities are performed is in the time-geographic approach based on the notion that individuals have goals and the activities performed aim to further these goals (Hägerstrand 1970, 1989, 2009).

To achieve these goals commonly multiple and different activities are required to be performed. In the time-geographic approach activities aiming at the same goal constitute a project (Hägerstrand 1970, 1985; Lenntorp 1998) and thus the multitude of activities described by the individual path emanate from various projects. Projects consequently are regarded as collections of activities that taken together aim towards advancing towards a goal (Hägerstrand 1973, 1974).

Projects can aim at anything from fulfilling basic needs, such as food and sleep for sustaining oneself, to the more complex, such as raising a child or work for gaining an income. An example of a project presented by Ellegård (1994) is the project "maintaining dental health" which includes the daily activity of brushing teeth but also visits to the dentist. These activities are interwoven with other daily activities of the individual. To carry out the activity of "visit the dentist" the individual must be at a specific place and at the specific time during the day. To be able to do this the individual must arrange other activities to support the "dentist visit" activity such as transport him- or herself to the location of the dentist. The individual in the example is a mother and there are other activities she also must perform prior to the visit. She has to arrange child care, transport the child to the caretaker, and after the dentist visit return to pick up the child. The stay at the dentist lasted for 30 minutes while the activity "dentist visit" in itself just used 15 minutes and the rest of the time was waiting. When the necessary transportation and child care arrangements are included the total time required for performing the activities 
increased to more than one hour. The aim of this project is to sustain dental health by a visit to the dentist, but many supplementary activities (child care, transportation and waiting) need to be carried out in order to fulfil this part of the "maintain dental health" project.

\section{The project context}

The concept project context can be utilised to discuss the way projects are fulfilled, as exemplified in the previous section. A project context is defined as the various specific appearances of all activities performed throughout one or more days in order to fulfil the goal of a specific project set up by an individual (Ellegård 1993, 1994b, 1999; Ellegård \& Vilhelmson 2004). The project context thereby gives relational meaning to the multitude of activities performed.

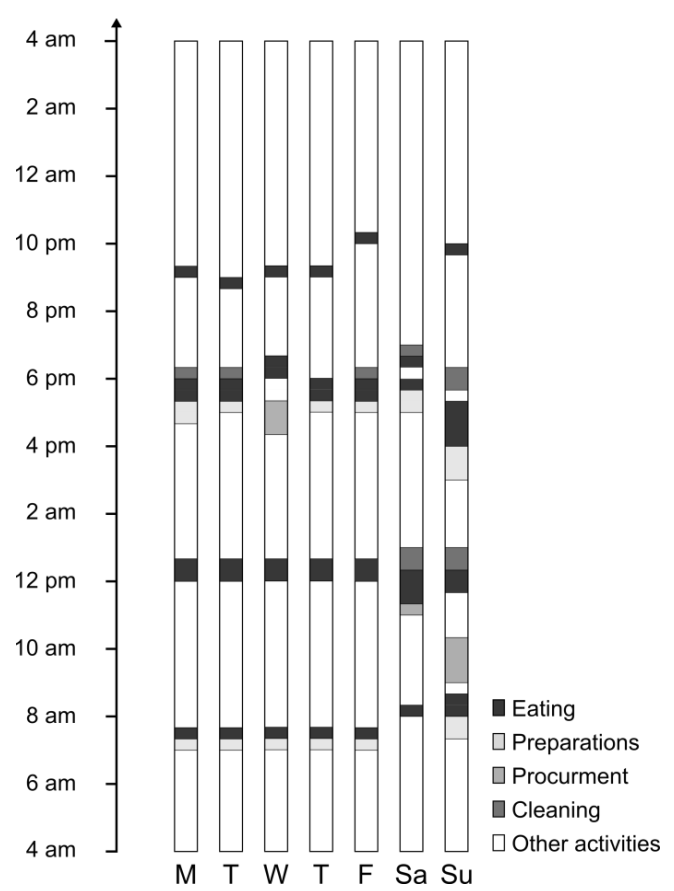

Figure 2.3: The project context for the project "having meals" throughout a week (from Hellgren [paper 4]). The days of the week are here placed side by side (rather than in a sequence) for the purpose of comparison between the days.

Projects are realised by individuals performing the necessary activities, but all activities aiming at achieving the goal of a project seldom are performed one after another in an uninterrupted sequence. Rather, the activities related to one specific project are intertwined with activities related to other projects, 
which is defined as the everyday activity context (Ellegård 1993, 1994b, 1999) which will be covered later. Occasionally, though, one activity that is part of one specific project also serves as a means also for fulfilling the goal of another project, and thus reaching a degree of synergy.

In Figure 2.3 activities which are performed in order to carry out the project "having meals" are displayed over the course of all days in a week. The project "having meals" consists of various activities, here procurement (performed on Wednesday, Saturday and Sunday), preparation of meals (everyday, but not all meals indicating that someone else prepares the meal), clearing the table (everyday but on weekdays only after the dinner) and, of course, eating (which is performed every day in a regular pattern). The activities of the project are spread over the days, from Monday (M) to Sunday (Su), and do not always appear directly before/after one another.

\section{Two kinds of projects}

Projects may be initiated by an individual or an organisation (Ellegård 1976, 2001) and thus there are individual and organisational projects. Individual projects are related to goals held by a singular individual, whereas organisational projects refers to common goals set up by group of individuals either in informal organisations, such as a families, or in formal organisations, such as companies.

Organisational, hence, projects can be casual and informal, such as in a family where common goals are negotiated and established and at least some activities for their achievement are performed collectively. Organisational projects can also be formal and authoritative, in companies, for example, the goals are formally set by a leadership and employees are hired to do specific work tasks (i.e. activities).

The individual and organisational projects commonly overlap, "employed work" as an individual project is one small component in the larger organisational project of a company where the individual is employed. The individual's work project also is a component of the family's organisational project since it yields an income. Individual projects may involve multiple individuals for their fulfilling since the activities of individual projects may be dependent on others to be performed.

Some projects are dominant (Hägerstrand 1985b:207), projects have different priority and some must to be carried out over others. Two examples of dominant projects are employed work and obtaining food. Humans need to eat on a regular basis and thus they must plan and organise their lives around the activities of this project. The project context of "having meals" shown in 
Figure 2.3 illustrates how meals regularly "occupy" parts of the daily sequence of activities.

\section{Projects in everyday life}

Neither projects nor the activities that constitute them are carried out in a vacuum. They compete with each other in regards to the individual's engagement regarding time, location and priority. Thus, the activities in an individual's everyday life are not independent and the different projects are interconnected through the individual's performance and how the activities interweave. Thus the activities performed by an individual in a day are not randomly stringed together in a sequence (Hägerstrand 1970; Ellegård 1999; Lenntorp 2005). What activities can be performed during a day is influenced by how long, when and where other activities are to be performed. It also depends on if the activities belong to a dominant project.

Living an everyday life mean that the individual create a daily sequence of activities that relate to the various different projects the individual wants to or has to be involved in. It must be possible to arrange the activities into a cohesive sequence that can be realised and is meaningful to the individual. Hence, the individual needs to structure and prioritise her various projects and their activities. Woven together the various activities that relate to different projects forms a context of its own, the everyday activity context.

\section{The everyday activity context}

The everyday activity context reveals how the various activities performed by an individual throughout the day are linked into the unbroken activity sequence of that day (Ellegård 1993, 1994b, 1999). Because the individual is engaged in achieving goals of several different projects, the activities all these are linked together into the sequence.

In order to illustrate we will return to our example individual John. In living an everyday life John performs a multitude of activities, as time passes they form a sequence of activities, or an individual activity path, throughout the day. In Figure 2.4 is an illustration of an everyday activity context showing that, as the day progresses ( $y$-axis) John performs different activities, here grouped into categories of activity ( $x$-axis). How these different activities are connected and shapes the day, in terms of what activities are performed, when they are performed, for how long they endure and in what order they appear, defines the everyday activity context.

The sequential order between activities is not arbitrary. It is linked to an underlying structure given by the individual and her informal organisations and by societal and other formal organisations' claims on the individual's 
presence and activity performance. Private habits and routines are developed and many of them stem from the rhythms of the biological needs - such as food and sleep - but they also are strongly influenced by the needs to coordinate with other activities and relate to other individuals.

The everyday activity context reveals the mundane and ordinary, and it is a harbour of familiarity and safety, but it occasionally also contains activities from projects that are unique which make the performance of the sequence less smooth. This individual mix of a multiple of variations in activities in the everyday activity context, then, reveals a daily rhythm of regularly occurring activities in combination with activities that less commonly are performed by the individual, like the dentist visit exemplified above.

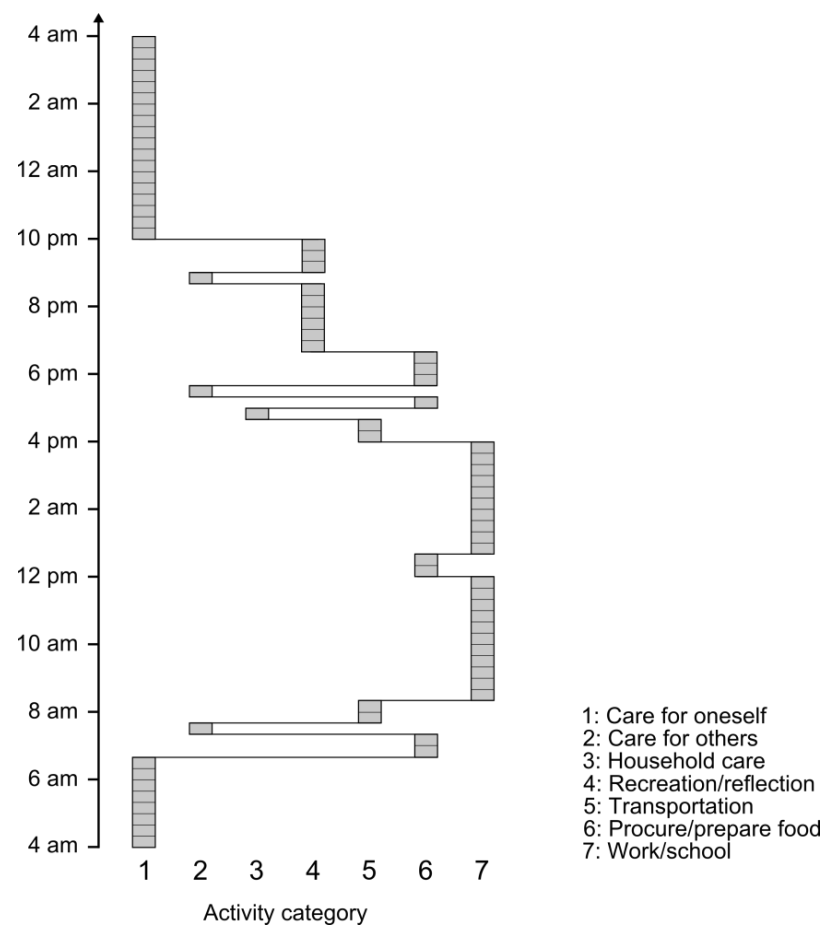

Figure 2.4: The everyday activity context described by an individual activity path. The individual activity path illustrates how the individual shifts between different activities, here grouped into activity categories, throughout the day (Ellegård 1993, 1994, 1999; Figure from Hellgren [paper 4]). The horizontal lines in this figure indicate a shift from one activity to another for facilitating the reading. Movements in the geographical space are simplified to the time the transportation activity takes.

The daily rhythm commonly includes activities such as cooking food, watching television and travelling, all which are examples of activities that use energy. This yields a regularity and rhythm to at least part of the energy use. 
As the activities of everyday life together form an everyday activity context, changes to save energy will have not only have an effect on the activity itself but also the everyday activity context.

Prioritising between activities related to various projects in every-day life can be related to the now-plane, here is regarded as a now-line since the spatial location is not represented, at which the opportunities to reach the intended goals which constantly are in flux and change. The individual must constantly plan and re-plan, prioritise and reprioritise, all while taking into consideration the restrictions set up by society and formal organisations to carry out required activities (contracted time structured by employer), to coordinate one's own activities with others (such as family members) and to adjust to one's own abilities. The individual, consequently, is constrained by things out of his or her own control.

\section{Constraints}

The individual has limitations in the ability to form and shape his or her individual path. These limitations to carry out an activity include factors such as the need for some activities to be coordinated among individuals (for labour, dinner, or social events), obligations towards others (such as employer, partner, or child), the choice to perform one activity over another due to limited time, access or lack of access to technology, or physical limitations. As the now-plane moves, continuously changing the present to the past, the individual have to overcome these constraints. The individual need to identify what opportunities, and limitations, these constraints offer depending on activities performed in the past and activities planned for the future (Whilborg 2005).

Hägerstrand (1970a) makes a distinction between three different constraints: capacity, authority and coupling. The three constraints were presented by Hägerstrand as aggregation of constraints, and he notes that "[i]t would be impossible to offer a comprehensive taxonomy of constraints seen as timespace phenomena." (Hägerstand 1970a:11) thus these constraints should be seen as conceptual rather than concrete limitations.

Capacity constraints are the limitations imposed upon the individual from biological functions as well as knowledge. The human body, with its two arms and legs, put limitations on interactions with the surrounding world. These can be overcome by technological aids and many of these aids uses energy. Access to technology such as a car can decrease the time needed to overcome a geographical distance which exceeds the range of the natural body. However, access to the technology in itself may not be enough, the knowledge of its use 
is equally important. Having access to a smartphone does not make its capacities fully accessible as knowledge on proper use of the smartphone is required.

Authority constraints relate to power and control, either official powers, such as laws and regulations, or more informal such as traditions and social acceptance of actions. Authority constraints are also related to dominant projects as these are generally governed by the individuals and organisations that hold power over the individual. This kind of constraint generally limits performance of activities to certain locations and time periods.

Coupling constraints relate to coordination between an individual and other individuals, material objects or places, in time and space. Daily social interactions between individuals in a household require the individuals to be at the same place at the same time. Many projects necessitate the individuals to be at a specific place to perform certain activities and this also might claim that other individuals are present at a specific place as well as it claims access to specific objects. As an example, for an individual such as the example individual John to go to the cinema with friends, he must coordinate with the others so they meet at the cinema (a specific geographic location) at a specific time. Many are the technological innovations that strive to overcome coupling constraints; telephone, internet and automation of services are some examples. However, many activities performed by individuals are social in their nature and are performed together with other individuals in a social context.

\section{The social context}

The social context is shaped by the individual's performing activities together with one or more other individuals (Ellegård 1999; Ellegård \& Vilhelmsson 2004). Organisational projects are shared between individuals and individuals perform the activities of such a project alone or together in different constellations. An example is the family's organisational project of raising a child where parents share responsibilities and perform various necessary activities either alone or together. Even individuals who normally are not a part of this organisational project can perform activities in it, such as relatives babysitting.

\subsubsection{The individual path on the move in time-space - prism and pocket of local order}

While constraints affect the activities performed there are two other limitations made by the time-geographic approach when it comes to how the day of individuals is structured: prism (Hägerstrand 1970; Lenntorp 1976; Miller 2005) and the principle of return. (Hägerstrand 1970, 1985; Lenntorp 1976) 
The space-time prism refers to the set of all points in the future time-space that potentially can be reached by an individual given a maximum possible speed from a starting point (at the now-plane) and with a specific an ending point in time-space (Hägerstrand 1970; Miller 1991; Kwan 1998). An important aspect of this potential is that, barring extraordinary events, individuals will have to return to their home at the end of the day for sleep. This principle of return is acts as a constraint on time away from the home, effecting which activities in various projects an individual can perform and for how long (Hägerstrand, 1985).

As an example of the prism and the principle of return let us revisit John and his visit to his friend. When John leaves his home there is a distance he can overcome with his means of transportation (the prism), before he needs to turn back to be able to return to his home for the evening (i.e. the principle of return).

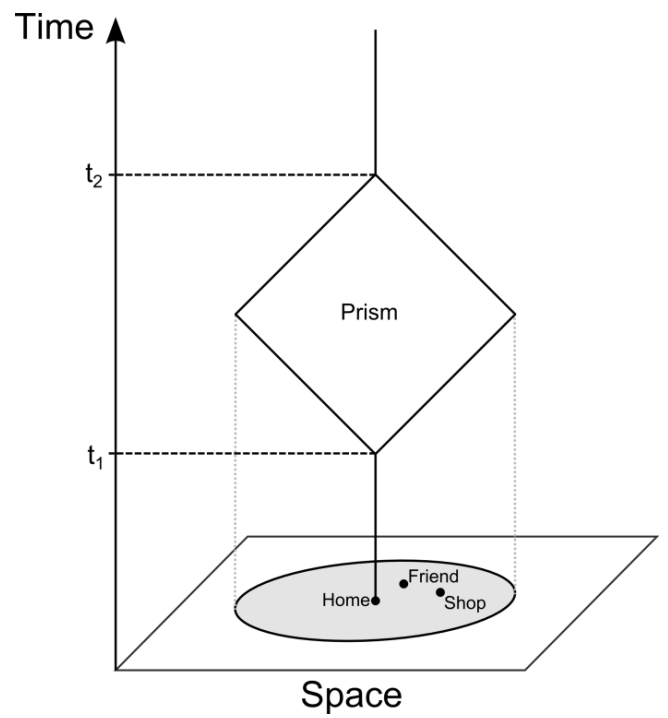

Figure 2.5: Space-time prism displaying the time-space volume in which the individual path potentially can move between leaving the home at time $t_{1}$ and returning at time $t_{2}$ (according to the principle of return).

In Figure 2.5 the potential area (grey) that John's individual path could reach during the time between two moments ( $t_{1}$ and $\left.t_{2}\right)$ is shown. The outer edge of this prism is where John would have to turn around on his journey to be able to return to his home at the second moment $\left(\mathrm{t}_{2}\right)$. The size of this prism is determined by the speed of the accessible means of transportation. In order to increase the width of his prism for a given time period John can choose a faster mean of transportation, such as a car compared to a bicycle. Considering 
different means of transportation, a fast mean of transportation usually is connected with high energy use.

Transportation activities are claimed in order for an individual to be able to realise the necessary activities related to a project in which some are separated by geographical distance. Then the prism becomes relevant: activities that increases, or decreases, the time needed for transportation effects the future potentials of the path and thereby how the individual can realise projects and their future activities. The principle of return is a salient part of this as individuals in everyday life generally will return to the home at some point during the day after leaving it. This need to return home to realise the projects within the home in combination with the requirements put on the individual, commonly authority constraints such as work, put a demand on how the prism can be structured. Then, in order to realise the furthering of the various goals of the individual, the prisms of the individual may restrict the opportunity for the individual to choose means of transportation. The prism shows within what geographical context the individual might perform his or her activities.

\section{The geographical context}

The geographical context refers to the fact that activities are performed at a geographic location during a period of time (Ellegård 1999). Activities may be bound to specific locations where there are prerequisites to their performance. Employed work must by some be performed at the workplace because of authority constraints. Activities for cooking dinner require certain apparatus, such as stove for cooking, which usually is located in the home. Consequently, all activities performed in the everyday activity context of an individual seldom can be performed at the same geographical location. Movements are necessary between locations if activities are to be performed at different locations.

Movements can be seen as activities in their own right but they also link activities together in the time-space. The geographical space in which the individual moves in combination with what means of transportation are available affect how movements between locations can happen and how much travel time will be needed to perform an activity at a different location compared to where the individual is located at the present.

\section{Location and projects - Pocket of local order}

In time-geography the concept pocket of local order is defined as a location in time-space that is organised and ordered for specific activities. It is a section of time-space in which the individuals both form and follow a specific order to 
conduct activities in projects. The activities performed in the distinct pocket of local order define and reproduce the order, based on the individual's aims and ambitions (Hägerstrand 1970; Lenntorp 1998; Ellegård \& Vilhelmson 2004; Wihlborg 2000)

As the order can change over time it is best to think of these pockets as sections in the time-space where a specific location for a period of time is arranged in a specific manner. In one pocket there can another pocket of local order at a lower level. Hence, pockets of local order compete in a hierarchical way, where some orders have the power to define others (Lenntorp 1998; Whilborg 2005; Whilborg and Palm 2008).

A home can be regarded as a pocket of local order as it relates to how things and projects are organised as the home is confined in the time-space, who is in control of what internal spaces, how and by whom activities are performed and what technologies there are to use for the household members' strivings to achieve the goals of their individual and organisational projects.

Individuals carry out many kinds of activities in their home, such as preparing and consuming meals, relaxing by watching $\mathrm{TV}$, reading and socialising, and sleeping. The home is ordered not just for temporary stays, but also for prolonged stays and the order is developed and withheld as well as developed by the individuals occupying it for their projects and interests.

An example of a pocket of local order is a singular flat (a home) in a block of flats. The block of flats in itself is a pocket of local order at another scale. The geographical area it covers has been ordered to accommodate the tenants, usually with infrastructure such as water and waste facilities, shops and park space. Within the block, then, a single flat creates a pocket of local order of its own which is ordered by its inhabitants in accordance with their projects, desires and tastes. As tenants move in and out of the flat over time the order of the flat might change considerable, while the order of the surrounding block of flats remains more or less the same. This is illustrated in Figure 2.6 where the flat ( $\mathrm{p}$, dark grey) occupy a section of the block of flats ( $\mathrm{P}$, lighter grey), which in itself is a larger pocket of local order occupying a section of time-space of the region it is located.

The home is in many ways the centre point in the daily lives of individuals, which is left in the morning for obligations such as work or for tasks such as shopping, and returned to later on for eating, relaxation and rest after performing the out-of-home activities. From an energy perspective, the home is a location where activity-generated energy use to a large extent is under the control of the individuals themselves. At work, the activities carried out are stipulated by the employer, at the store by the store owner, but in the home, 
the individuals decide what activity to perform and when. Although the individuals may have limited capacity to affect the energy use of heating, the appliances' technical functionality and the effect of the building structure, they can influence what electric appliances to buy and the activities they perform when using the appliances. These are important point of departure for the coming discussions in this thesis

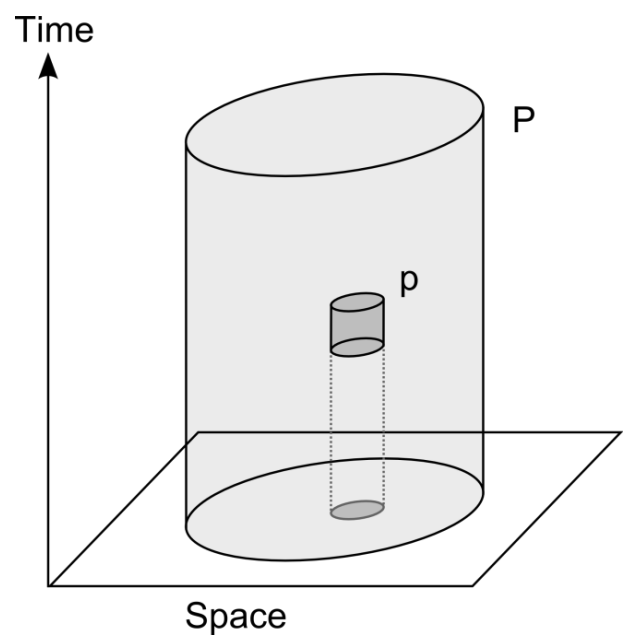

Figure 2.6: Pockets of local order, the smaller pocket (p) of a flat within the larger pocket (P) of the block of flats 



\section{3 \\ Methodological APPROACH}

In the introduction it was stated that the data material used in this thesis, time use diaries, contains the sequence of activities performed by individuals in their everyday life. Further an argument presented in the introduction is that these sequences are the manifestation of the motivations and ambitions of the individuals. In the theoretical grounding the theoretical arguments to approach individuals in everyday life from how their sequence of activities is formed were laid out. The methodological approach used in this thesis is based upon these arguments.

The choice of methodical approach partly stems from the data material. The main data material used in this thesis is the 2010/11 Swedish Time Use Survey (STUS) where respondents filled out time use diaries and completed an accompanying survey. Time use diaries as a method of data collection have a long history, but the modern usage can be said to origin from the multinational time use study directed by Alexander Szalai (1972) in 1965. Szalai's team introduced an activity coding scheme and propositions for a variety of analytical approaches, some of which are still used in contemporary studies.

The layout of this chapter will be in three sections. The first section centres on the character of time use data (3.1). The second section is a discussion of the data material used and the effects of how the activities in data material are coded (3.2). The final section will cover considerations of the choice of method and the methods employed in the thesis (3.3).

\subsection{Time use diaries}

The discussion on the character of time use data will be broken up in four parts, the first part (3.1.1) will discuss more generally how time use can be 
measured whereas the second part (3.1.2) will give a background on the data collection the method for the data used in this thesis, time-diary data collection. After this the diaries themselves will be covered, how they are collected (3.1.3) and the nature of the data they yield (3.1.4).

\subsubsection{Measuring time use}

Time use can be measured in many ways depending on how time use is defined. In this thesis time use is defined as the period of time passing when an individual carries out an activity, thus definitions that take experiences and perceptions of time use into consideration will be excluded. Time use, as defined here, can be collected by time use diaries, time use stylised measurements or experiential sampling (Juster et al. 2003).

Stylised measurement methods are when the respondent is asked to retroactively estimate the average time they have used on various activities. The questions asked are such as "How many hours on average do you work in a week?" Stylised methods tend to have a bias of over- or underestimates of actual time used for activities (Bonke 2005; Kan 2008; Kan \& Pudney 2008; Otterbach \& Sousa-Poza 2010; Ricci et al. 1995; Robinson et al. 2011). Also, data collected by stylised methods tend to focus on singular activities of interest for the specific study and rarely take into account when the activity was carried out or within which context. Stylised methods generally yield estimated averages of an activity or a set of activities.

In experiential sampling methods the respondent reports their activity, and answers supplemental questions, at randomised points in time. These points in time are commonly triggered by the use of an electronic pager. Experiential sampling methods offer lower bias and more exact discrete, snap-shot, data than stylised methods. Experiential sampling methods yields what an individual is doing at randomised times and typically do not collect data about what happens in between them. It thus lacks the flow, or sequence, of activities throughout the day.

Time-diary data collection is a method where the respondents report what activities they perform during a specified period of time, commonly a 24 hour period. The time-diary will, if filled in correctly, contain all activities performed by the respondent, when and where these activities where performed, for how long and commonly with whom. In contrast to methods where an individual is asked to estimate how long time he or she spends on a specific activity, such as watching TV, time use diaries tend to largely avoid problems such as individual over- and underestimation and social desirability bias. 
These different approaches have strengths and weaknesses (Bonke 2005; Juster et al. 2003; Otterbach \& Sousa-Poza 2010). The approach used in this thesis builds on the idea that the day is filled by many different activities performed in a sequential order that all are part of various projects which the individual attempts to carry out, since both each one of them and the combination of them in some way are meaningful for him or her. In order to analyse daily life from this approach the data needs to reflect the whole day of the individuals in the study. Out of these three methods of data collection only time use diaries yields a full day of activities and the sequence of them for each individual and thus this is the type of data that has been used.

\subsubsection{Time-diary data collection}

Time use studies in various forms have been carried out in over 90 countries since the very earliest were done in 1857; over 50 have been carried out after the year 2000 (Fisher et al. 2009). Time use diaries has been used for research purposes in different subject areas such as employment and labour (Boone et al. 2009; Claessens et al. 2010; Krueger \& Mueller 2010), leisure time and "active living" (Beck \& Arnold 2009; Millward \& Spinney 2011; Spinney et al. 2011), and gender (Dribe \& Stanfors 2009; Motiram and Osberg 2009; Schneider 2011). It has been applied in studying mental health (Bejerholm \& Eklund 2006; Yanos et al. 2010) as well as family life (Bianchi and Robinson 1997; Brown et al.2010, Dribe \& Stanfors 2009). Time use data have also been used to model energy use (Karlsson \& Widén 2008, Widén \& Wäckelgård 2010, Widén 2010). If repeated data collections are done, time use data allows for studies of longitudinal changes over time (Sullivan \& Gershuny 2001).

Today there are two broad branches of large-scale data collection of time use diaries. One follows the work of Szalai (1972) and Harvey (1993) whereas another development is the American Time Use Survey (ATUS) by the US Bureau of Labor Statistics (ATUS, 2013). Of these the Szalai/Harvey model is the dominant and it is this approach that forms the basis for the Harmonised European Time-Use Study (HETUS) and the United Nations (2013) lead The United Nations lead Task Force on Time Use Surveys. There has been multiple small-scale data collection, many follow the Szalai/Harvey model however there are many variations. These small-scale data collections generally do not have the intent of quantifying the collected data in the same way as those that follow the Szalai/Harvey model or ATUS.

The studies that follow the Szalai/Harvey model commonly use paper based time-diary surveys with an attached questionnaire for background variables. One of the great strengths of paper time-diary forms is that they record what 
people do and when. Rather than asking people how much time they spend on a certain activity this information can be extracted from the diary. Several studies (cf. Bonke 2005 and Kan 2006) show that individuals tend both to overand underestimate the time they spend on activities when asked to give a number in interviews and surveys. Time-diaries are recorded "as it happens" and can capture activities that are taken for granted and therefore commonly "disappear" in the noise of everyday life activities if asked about in interviews or questionnaires.

A notable disadvantage of paper time-diaries is that the recording of events interferes with common day to day activities and requires the respondents to be stringent in their notation. Even though this disadvantages will interfere and have an effect the data it can be considered minor in comparison to the recollection methods employed. For the paper surveys control questions are included to ensure and strengthen data validity.

In difference to the Szalai/Harvey model the American Time Use Survey uses telephone interviews. In these the interviewee is asked to sequentially reconstruct a prior day; answering question on when, for how long, what activity was carried out and where the individual were. Telephone interviews have the benefit of being more cost effective whereas paper diaries have the potential to record minor activities and therefore potentially yield a more accurate picture of everyday life activities. ATUS data validation is conducted as the data is collected via interviewee feedback.

A comparison of the two different approaches, reconstructive telephone interviews (i.e. ATUS) and the paper diary version (used by those following the Szalai/Harvey model), gives that both methods have strengths and weaknesses. Telephone interviews have the benefit of being more cost effective, while paper diaries if are they are recorded continuously are more accurate, however the accuracy is lessened if the survey is filled in retrospectively. The data used in this thesis follow the Szalai/Harvey model.

\subsubsection{Time-diary survey}

Time use diaries offer the possibility to record the activities as they occur rather than recollecting after the activity the activity have transpired. The activities in the making are of immediate interest to the individual diarist since they make up the day for him or her. The recording of activities in the diaries can be done in various ways. One way is to ask the participant to use their own words to describe the activity they perform. These descriptions are later categorised by the researcher or the data collector. Another way is to instruct the participants to use predetermined fixed categories for reporting their 
activities. The benefit of using the participant's own words is that it better captures what activity they are performing. A downside is that it adds complexity, cost and time for coding the diaries collected.

Data can be collected with variable time, where the respondent notes start time, and in some cases also the end time of an activity, alternatively data can be collected in diary forms utilising fixed time intervals. Both have advantages and drawbacks. On one hand, for example using flexible time allows for greater precision of the timing for the recorded activity however the reliability of this precision can be questioned. Using fixed time intervals, on the other hand, encounters the problem of losing activities with short duration since the most time consuming activity is to be recorded for each time interval.

A time-diary commonly covers a specific period of time such as a day, more rarely a week, or a month. The HETUS guideline (Eurostat 2009) recommends data to be collected for two days: a weekday and a weekend day. A drawback of this is that the data only yields a snapshot of two singular days and how these days fit into the greater flow of everyday life is not captured. The HETUS limitation to one weekday and one weekend day is due to economic limitations and to reduce recording fatigue of the respondents (Gershuny 2011). The "two-day" data collection commonly contains question on how well this day represent an "average day" for the respondent to ensure validity.

The collected time use diaries thus consist of sequences of activities, either as of discrete sequences or continuous ordered activities. From this data information about when and for how long the individual have carried out various activities can be extracted for analysis. Thus at its core it has two features: it measures when during the day the activity took place (timing), it shows how long each activity has been carried out (duration) and in addition the number of times an activity occurs in the course of the day (frequency).

Additionally, background information on socioeconomic factors of the respondents' is generally collected. Usually the purpose of the background information is to form population groups for which aggregates can be calculated.

When it comes to recording the activities the harmonised European time use survey (2009) uses the four following recording domains:

- Main activity: "What did you do?"

- Parallel or secondary activity: "Did you do anything else? If so, what?"

- With whom: "Were you alone or together with somebody you know, if so, who?",

- Location (including mode of transport) 


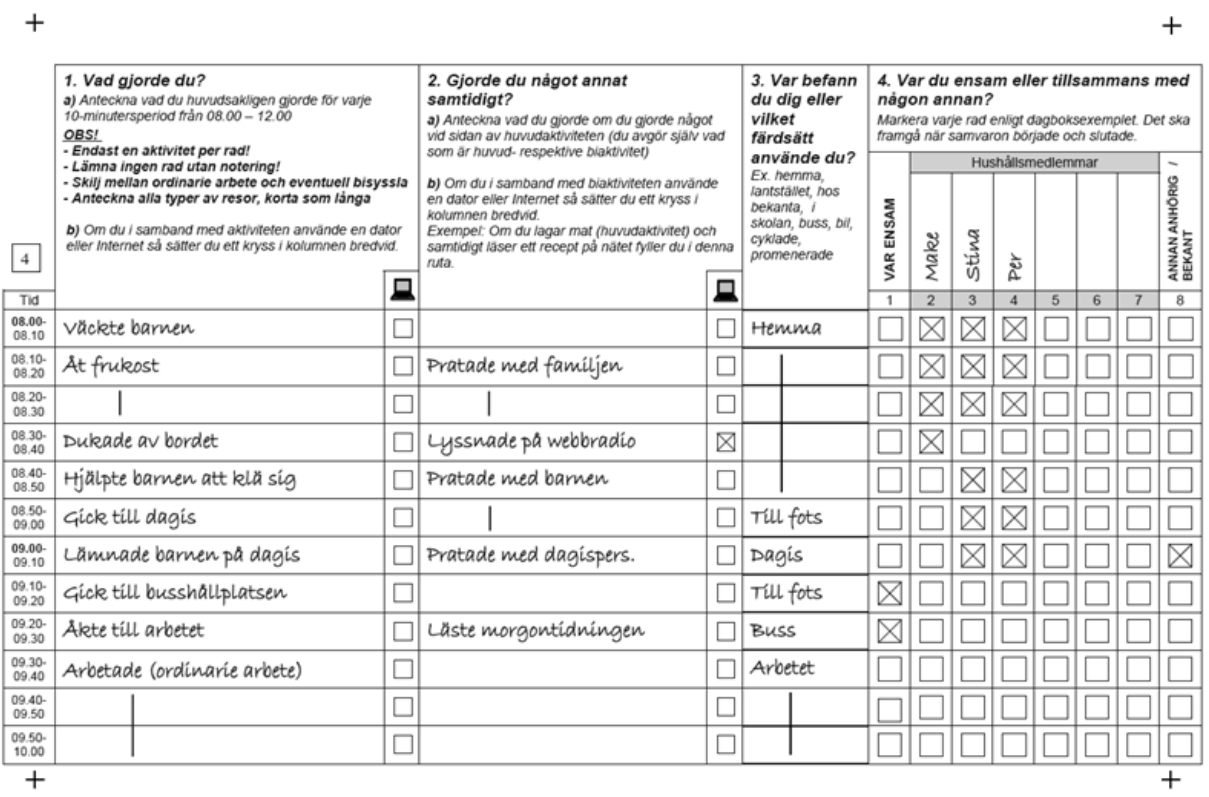

Figure 3.1: The layout of the time-diary portion of the 2010/11 Swedish time-diary survey. The recorded entries are example data (Source: Statistics Sweden, Tidsanvändningsstudien 2010/11, reprinted with permission)

As already indicated, the activities performed can be measured in two distinct ways, either by having the respondent freely fill in the time or by asking the participants to note the main activity during a pre-set period of time.

Figure 3.1 displays an example of how a diary is laid out and it contains example data. This particular example is taken from the instructions accompanying the 2010 Swedish time-use survey ${ }^{5}$. The leftmost column contains the 10-minute intervals used, the second column (" 1 . Vad giorde $\left.\mathrm{du} ?^{\prime \prime}\right)^{6}$ is where the main activity is written down, the third ("2. Gjorde du något annat samtidigt?") $)^{7}$ is for activities undertaken simultaneous or in parallel (such as listening to the radio while washing dishes). The computer symbol in the second and third column is to be crossed if a computer, tablet or smart phone was used in conjunction with or to perform the activity (such as reading the news on the Internet).

\footnotetext{
5 A digital copy of the 2010 time-diary and respondent information can be found at http://www.scb.se/Statistik/LE/LE0103/_dokument/Tidsdagboken.pdf (retrieved 2014-04-14)

${ }^{6}$ English translation: What did you do?

${ }^{7}$ English translation: Did you do anything else at the same time?
} 
The fourth ("3. Var befann du dig eller vilket färdsätt använde du?") ${ }^{8}$ records the location or mode of transportation if the individual is travelling. The fifth ("4. Var du ensam eller tillsammans med någon annan?") ${ }^{9}$ contains multiple sub-columns; the first one is to be crossed if the individual is alone whereas the other contains the possibility to note names of family members and one last category for "other" unspecified individuals.

\subsubsection{Time-diary data}

The data collected with time use diaries consist of sequentially ordered episodes (activity occurrences). These episodes contain at minimum information on what activity was performed, when the episode started and when it end, and the length of time the episode took. In accordance to the guidelines, such as HETUS or ATUS, additional information is collected on the episodes. Information such as the location, in the case of travel the mode of transportation is noted, as well as with or for who the episode was undertaken.

Which activity that is performed is recorded either in predetermined categories or recorded verbatim which are later categorised. The Swedish time-use survey of 2010/11 used a combined system of automated text recognition and human interaction to code the activities into categories. In a first step the hand written record of what activity that was performed was analysed by automated text recognition software and later validated by a human. In the case the software was not able to interpret the recorded activity, manual (human) coding was done. Generally the length is coded by noting start and stopping time or how many predetermined blocks of time (such as the 10-minute blocks) the activity (episode) took. Since the episodes are recorded in sequential order the net result is the sequence of activities that the respondent has undertaken during the measured period.

Time-diary data can be coded for computer analysis in different ways (Gabadinho et al. 2011) and a common way to handle time use data is the SPELL-format, see Table 3.1 for an example, wherein every episode is recorded as a row. The id column contains a unique identification number of the individuals surveyed, and is used to identify who has carried out the episode. Index indicates the order of the listed episode. Start time and End time yields the clock time for the activity and Minutes the length. Activity and Location yields the "what" and "where" of the episode. The Alone column

\footnotetext{
${ }^{8}$ English translation: Where were you or what mode of transportation did you use?

${ }^{9}$ English translation: Were you alone or together with someone else?
} 
records whenever the individual carried out the activity in the episode alone or not and further, not shown here, are columns containing other individuals.

Table 3.1: Example of coded time-diary data using SPELL format

\begin{tabular}{cccccllll}
\hline ID & index & $\begin{array}{c}\text { Start } \\
\text { time }\end{array}$ & $\begin{array}{c}\text { End } \\
\text { time }\end{array}$ & Minutes & Activity & Location & Alone & $\ldots$ \\
\hline$\ldots$ & $\ldots$ & $\ldots$ & $\ldots$ & $\ldots$ & $\ldots$ & $\ldots$ & $\ldots$ & $\ldots$ \\
1 & 5 & $07: 10$ & $07: 20$ & 10 & $\begin{array}{l}\text { Getting } \\
\text { dressed }\end{array}$ & Home & No & $\ldots$ \\
& & & & & & & & \\
1 & 6 & $07: 20$ & $07: 50$ & 30 & Travel to work & Car & Yes & $\ldots$ \\
$\ldots$ & $\ldots$ & $\ldots$ & $\ldots$ & $\ldots$ & $\ldots$ & $\ldots$ & $\ldots$ & $\ldots$ \\
1 & 11 & $17: 30$ & $12: 50$ & 20 & Shopping & Supermarket & No & $\ldots$ \\
$\ldots$ & $\ldots$ & $\ldots$ & $\ldots$ & $\ldots$ & $\ldots$ & $\ldots$ & $\ldots$ & $\ldots$ \\
\hline
\end{tabular}

In addition to this each row may contain information on computer use (present in the STUS), for whom the activity was performed (not present in STUS) and other information concerning the episode that was deemed relevant by the survey organiser.

Taking into account the recorded data, and the structure of how it is coded, a number of components can be extracted:

- What activities has been carried out

- For how long

- When during the measured period (clock time of the day in case of diaries measuring a day)

- Number of episodes containing the same activity

- In which order the episodes of the same activity took place

From an analytical perspective time-diary data is a sequence of states where the episodes represent activities and the sequence the order and duration of activities.

\subsection{Data used, its coding and application}

The data used in this thesis is the Swedish time-use survey pilot ${ }^{10}$ of 1996 and the official time use survey (STUS) of 2010/11. The time use surveys were conducted by Statistics Sweden and the surveys are described in 3.2.1.

The categorisation of daily activities in the data material supplied by statistics Sweden has been recoded for this thesis. A discussion on the

${ }^{10}$ As the 1996 was a pilot study it has not been used in official reports. 
motivation and how these have been recoded can be found in 3.2.2. Closing this part is a discussion on the model used to estimate energy use from activities performed in everyday life (3.2.3).

\subsubsection{The time-diary data used in this thesis}

The Swedish time-use survey pilot of 1996 was used in paper I and the official time use survey of 2010/11 were used in paper II, III and IV. The 1996 data set was used in paper I due to that the 2010/11 survey was not accessible at the time. Since paper I is a methodological paper the impact of using a different data set is considered to be minor.

The studies are similar in that they in both surveys participants recorded their main, and optionally their secondary, activities for a 24-hour period from $4 \mathrm{am}$ to 4 am the following day. Both also recorded the participants' location (such as "at home" or "at work") and who they were together with. In both the respondents were asked to fill out a diary on two separate days, one weekday and one weekend day.

In both surveys time was recorded in the same way, using 10-minutes intervals to be filled in by noting the activity that took the longest time to perform. However, when the 1996 study was recoded (Ellegård 1993, 1994) from the raw diary data, some 10-minute episodes were divided into shorter time periods since there was more than one activity noted in the line for Activity, giving the time episodes variable length. No such changes are done in the recoding of the 2010/2011 diary data. Statistics Sweden is an active participant in the work of the HETUS and its standardisation of time-diary surveys and the 2010/11 study more closely followed the guidelines set by HETUS (Eurostat 2009) compared to the 1996 pilot study. Additionally in the 2010/11 survey the respondents were asked to tick a box if they used information technologies (see Figure 3.1) which were not the case in the 1996 study.

The pilot study of 1996 targeted members of households over 10 years of age. Data was collected from about 460 individuals in about 190 households. The 2010/11 survey study used an individual sampling, with a smaller subsample of where the cohabitant partner was asked to participate. The 2010/11 survey collected data from 3292 individuals between the ages of 15-84.

\subsubsection{Activity categories}

The analysis in this thesis concerns energy use of indivisible individuals in the sequential course of their everyday life. Therefore, not only the sequential nature of time-diary data is crucial but also how the activities are categorised. 
There are various types of activity categorisation; the most frequently used is based on the HETUS guidelines (Eurostat 2009). The HETUS categorisation of activities is based on the work by Harvey and Niemi (1994) and it is a simplification of the UN ICATUS coding scheme (United Nations Statistics Division, 2015a). The UN ICATUS, and thus the HETUS, classification have an origin in the production boundaries of the System of National Accounts (United Nations Statistics Division, 2015b) which was development to analyse relations between paid and un-paid work. Therefore activities that are assumed to be un-paid work are collected into the same category: household chores.

Another category scheme, based on the time-geographic approach, was developed by Ellegård and Nordell (Ellegård 1993, 1994, 1999, Ellegård \& Nordell 1997) which takes the individual and her/his daily activities as a point of departure to explore the assumed individual aim to "live one's life". It is developed with a perspective "from below" and was initially based on about 200 very detailed time-diaries written by individuals writing diaries during one summer week and one winter week each.

The approach related to its label "EGCS", which stands for Empirically Generated Category Scheme (Ellegård 2006). A difference between the HETUS and the EGCS categorisation schemes is the number of activities appearing at the main level of activity classification. The HETUS scheme involves five activity categories while the time-geographic EGCS category scheme has seven categories (see Table 3.2). This is of importance when overall analyses are made as lower resolution might hide important information about what kind of activity actually is performed which is especially important within the category household chores.

Table 3.2: The main categories of HETUS and EGCS

\begin{tabular}{ll}
\hline Main categories in HETUS & Main categories in EGCS \\
\hline 1 Employed work & 1 Care for oneself \\
2 Household chores & 2 Care for others \\
3 School & 3 Household care \\
4 Personal needs & 4 Reflection/recreation \\
5 Free time & 5 Transportation \\
& 6 Procure and prepare food \\
& 7 Employed work/school \\
\hline
\end{tabular}

All analysis in this thesis is based on the EGCS categorisation scheme. The data of the 1996 survey used in this thesis had already been classified in accordance with the EGCS. For the 2010/11 survey all activity classifications in the data material supplied by Statistics Sweden were evaluated at the most 
detailed level and matched with corresponding EGCS classification. This matching was then used for recoding of the data material.

\subsubsection{Energy use and daily activities}

Individuals' energy use relates to their use of electric appliances, vehicles and other apparatuses claiming energy for their services. Widén (2010) developed a model relating the activities performed in the home to the energy used by electric appliances.

As there are differences in how appliances and activities relates two schemes of electricity use were presented: firstly, one in which electricity is demanded during the performance of an activity (such as a vacuum cleaner) and, secondly, one in which electricity is demanded after a specific activity has been performed (such as turning on the washing machine). The runtime of the appliance for the first model equals the activity duration, while the runtime for the appliances in the second scheme is set to a limited time period. The specific values used in the thesis are taken from Widén et al. (2009) and can be found in table 3.3.

Table 3.3: Energy demand, from Widén et al. (2009:767).

\begin{tabular}{lll}
\hline Activity & Power (W) & $\begin{array}{l}\text { Run time } \\
\text { (min) }\end{array}$ \\
\hline Audio & 100 & - \\
Cleaning & 1000 & - \\
Computer use & 100 & - \\
Cooking & 1500 & - \\
Dish washing & 430 & 160 \\
Drying & 1650 & 90 \\
Ironing & 1000 & - \\
TV & 200 & - \\
\hline
\end{tabular}

This is a simple way to estimate electrical energy use that is generated from everyday activities in the home. However, not covered by the model is energy use emanating from heating, hot water, ventilation, cold appliances and transportation. Heating and hot water are of major importance for energy use, they are, together with ventilation and cold appliances, excluded in this analysis. With exception from use of hot water (Krantz 2005; Krantz 2012), the latter forms of energy use are not to a large extent depending on what activities people perform. Indirectly, heating is related to people being in their home and what appliances they use (Karresand 2014, Isaksson 2009). To avoid making the analysis more complex heating and water is excluded. Further the 
activity of personal transportation is not included in the energy use of the residential sector (this is the focus of paper III).

To estimate energy use of transportation a novel approach was used. The average energy use from different means of transportation per individual and travelled kilometre was used as a base. In assuming an average speed these values could be used to estimate the energy use per 10 minute episode of travel.

\subsection{Method employed}

Approaching everyday life from the perspective of sequences of activities leads to the realisation that more traditional methods such as regression analysis are problematic. This part will start with a discussion on analysing time-diary data and arguments regarding the problem of applying more traditional methods (3.3.1) before moving to discuss the methods employed: sequence analysis (3.3.2) and clustering (3.3.3).

\subsubsection{Considerations of analysing time use diaries}

There are different approaches to analyse time-diary data and these different approaches lean on different perceptions of time which impact how time use is analysed and what results to expect. Philip J. Stone (in Szalai 1972:96-97) describes three levels of analysis that can be used to classify analytical approaches:

At the first level the analytical approach is to use aggregated time used or frequencies of activities and then compare these with various demographic variables. At this level of analysis, time-diary data is analysed by totalling the time the individual spend on a specific activity during a day and use this as the basis for searching for differences between, or dependencies on, background variables.

The second level uses the average time use or frequencies of combinations of activities, identities of parties with whom activities were performed with, and location information. This expands on the first level by adding more independent variables to the analysis, essentially moving from bivariate methods such as $t$-tests to multivariate tests such as regression.

The third level turns the focus of the analysis on to the sequence of activities. This means that there is a rather stark difference between this level of analysis and the previous two. The difference is illustrated in Figure 3.2 where a seeing the day as a sequence of activities (left) is compared to seeing the activities of the day collapsed into aggregates (right). On the left hand side the activities are understood and analysed as a sequence of activities where 
the order duration and the repetition of activities are taken into account. On the right hand side the order duration and the repetition of activities is collapsed into the summarised time for each activity. The difference of seeing the day as divided into sums of time spent performing an activity (level I and II) compared to approaching the day as a sequence of activities (level III) is that in the first two levels the amount of time spent (duration) on an activity matters and is the analytical unit. In difference the third level has the sequential order of the activities is the main unit of analysis.

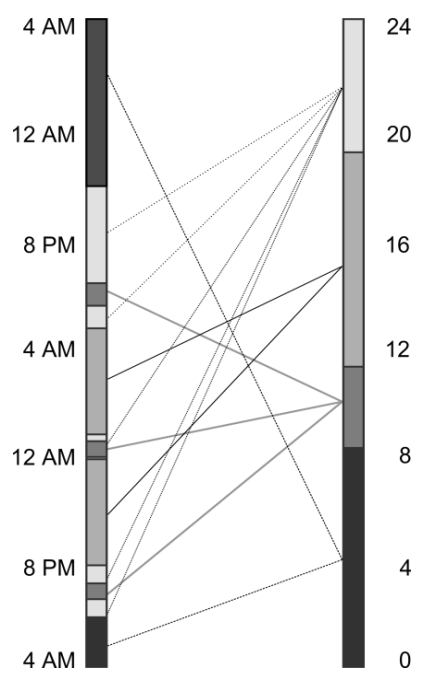

Figure 3.2: Sequence of activities in the course of a day (left) and on the right the same activities collapsed into a $24 \mathrm{~h}$ aggregates (right), adapted from Hellgren (2014; paper I)

Putting focus on the sequence of activities emphasises a perspective on the daily activities as a context which help to explore how the day is formed by many intertwined activities. Activities such as raising children, working, socialising with family and friends, taking care of the home, sleeping, and eating are all essential to daily life and are usually performed now and then during the day. Trying to fit all these activities into the limited time frame of a day requires that individuals make choices about what activities to carry out and when to carry them out in relation to other activities and other people during the day.

It is in this sense that the more traditional methods become problematic. A common application of regression modelling is to start to summarise the time an individual has spent on a specific activity over the measured period (such as a day). This sum of time for the activity can then be used in a regression model, most commonly as an outcome variable. Regression offers the ability to 
analyse the summarised time and how variations in background variables give rise to variations in time used. In approaching time use from the perspective of background variables this is a powerful approach, however this is not the approach taken in this thesis.

This use of regression models tend to lead to an analysis on the first or second level mentioned above as it discards some of the information that can be extracted from time-diary data, namely when during the day the activity was carried out and the number of episodes it was carried out in.

In part the problem arises from how regression analysis works. Regression is simplified an estimation or prediction of relationships between variables. Regression uses the relationship between a variable (outcome variable) and one or more other variables (predictor variables) variable to estimate the values of the outcome variable. Regression modelling can be expressed as $E(Y)=f(\boldsymbol{X}, \boldsymbol{\beta})$ where $E(Y)$ is estimated value of the outcome variable $Y$ and $f(\boldsymbol{X}, \boldsymbol{\beta})$, is a function of a single or multiple predictor variable(s) $X$ and regression coefficient(s) $\beta$. This means that regression is exploring the effect of the variability of predicators upon the outcome variable. For analysing time use this usually means that what is analysed is how variations in background variables effect the time used on a specific activity.

Regression analysis is a powerful approach to analyse time-use. At its core it yields information on how variations in background variables covaries with length of time spent on specific activities. This does however mean that it is the variations of background variables that is analysed. This is based on the concept that variations in time used for a specific activity is dependent on variations in predictor variables; external variables, variations of summarised time of other activities, or the number of episodes. When the activity occur is commonly are lost and the focus on a singular activity other activities that occur during the day are generally ignored as the focus is on a specific activity.

Survival analysis ${ }^{11}$ is a less commonly used but powerful approach to analyse time-diary data. At its core survival analysis seeks out to analyse the timing of events, or put differently the time to an event. For this survival analysis has three basic elements: a time origin, a scale for measuring time, and an event (Broström 2011). Essentially survival analysis explores the time between a start (origin) and the occurrence of the event. As an example the time between leaving for work (origin) and returning home (event) may be analysed with survival analysis.

\footnotetext{
${ }^{11}$ In social science survival analysis is commonly called "event history analysis". The differentiation is usually used in social sciences to denote an application where the event can be repeated, such as unemployment (Steele 2005). Here the more generic survival analysis will be used.
} 
Repeated activities can be handles in a single survival analysis. In the terminology of survival analysis it is the timing between the occurrence of the first, second and so during the specified time period. While multiple survival analysis could be used, each for each occurrence this is fraught with problems, mainly because the reasons for dissolution may not be the same in each analysis (Steele 2005). A joint model, where the repeating events are included, is preferable. This due to that the model can then include random effects that represents unobserved factors of risk. It should be noted that repeated events are still considering one event, though now it can appear multiple times. In time-use data this could be the event of eating food, whenever it is breakfast, lunch or dinner.

Survival analysis is a strong approach to analyse time-use if the goal is to find aggregated probabilities, or risks, for when a predetermined activity occur. Further it is a fruitful method to apply to find differences between groups in how these change over time. It does however not take into account the length of time the activity, or what activities preceded or occurs after the specified activity. It can, in more advanced models, handle whenever predetermined activities have occurred prior or after the specified activity, but these needs to be explicit set. Thus survival analysis does not really take into account the whole sequence of events.

Survival analysis has an advantage when it comes to handle time-diary data compared to regression analysis in that it does take the "when" into account, while it has a weakness compared to regression in that it does not include the "for how long" as survival analysis is focused on the occurrence of an event. Both methods can explore and handle the influence of external variables ${ }^{12}$ however none of the focus on the sequence of activities.

\subsubsection{Sequence analysis and optimal matching}

The main method employed in this thesis is sequence analysis. Sequence analysis in itself originated from research in computer science that Richard Hamming and Vladimir Levenshtein conducted in the 1950s and '60s (Hamming 1950; Levenshtein 1966). The research has mainly found its applications in bioinformatics, where methods have been developed to analyse DNA, RNA or peptide sequences, but have more recently been used within social sciences. Since the late 1980s Andrew Abbot (Abbott 1990, 1995, Abbott and Hrycak 1990, Abbott and Tsay 2000) have been advocating and

\footnotetext{
12 The term "External variables" is here used to denote data that generally are collected together with the time-diary but are not direct measurements of time use. Included in this are variables such as sex, age, and other social indicators.
} 
developing the optimal matching approach. Steaming from Abbott's vocabulary, within the social sciences sequence analysis is more commonly known as optimal matching.

The basic idea behind sequence analysis is to find patterns in discrete sequences, usually by comparing sequences in order to find similarities. The developments within biosciences have been translated to the social sciences in that sequences can be found in social environments. A common application of sequence analysis in social science is that of life courses. By using, as an example, years the sequence of the main occupation of the individual during their life can be explored with the intent of finding individuals that have similar trajectories through their life.

Billari and Piccarreta (2005) argue that using sequence analysis offers an approach where the complete life course is taken into account; it offers a holistic perspective on the life course. The attractive feature of sequence analysis is that it takes the whole sequence of events through a life course into account. Sequence analysis allows for the identification of typical sequences and the ability to group these together via the use of clustering techniques.

\section{Adapting sequence analysis for time-diary data}

Time-diary data have similarities to life course data. They can both be expressed in discrete steps, each step containing information on what the step contains. They are both ordered sequentially, age 26 is preceded by age 25 , and 14:50 is preceded by 14:49. For time-diary data the steps can be chosen to be in minutes or other predetermined steps. The 2010/11 Swedish time-use survey used 10-minute blocks to record the activities and thus these can be used.

There is however a difference in that life course history is definite. A life course taken cannot, by the same individual, be relived whereas the time-diary method captures smaller segments of time, commonly a day, which might be performed in a similar order another day (what usually is known as repetition and routines). Thus the events during a singular day measured by time use diaries may be atypical, containing activities rarely performed or missing commonly performed activities that for one reason or another were not performed that day. While this does not directly affect the outcome of a sequence analysis it does require the interpretation to be more nuanced.

\section{How sequence analysis works}

Sequence analysis is an algorithmic analysis of sequences which, in a very simplified way, works by taking one sequence and then trying to "make it" into another sequence. This can be done in two ways: (i) either by substituting 
one state of a sequence for another or by (ii) insert one state and delete another (referred to as "indel", short for insertion/deletion).

To use an example, let us take two sequences ${ }^{13}, S_{1}$ and $S_{2}$. In the example the sequences have three possible states $\{A, B, C\}$ and consists of six activities (a length of 6).

$$
\begin{aligned}
& S_{1}=(A, A, A, B, B, C) \\
& S_{2}=(A, A, B, C, C, C)
\end{aligned}
$$

Both sequences consist of six states, and have three possible activities in them: $A, B$ and $C$. If $S_{2}$ is to be made into $S_{1}$ the third activity needs to be changed from a $B$ to an $A$, and fourth and fifth needs to be changed into a $B$. In optimal matching there are three ways this can be done:

- A state can be inserted

- A state can be deleted

- A state can be substituted

Insertion works by adding a new state to the sequence; in the example with $S_{1}$ and $S_{2}$ this means that in order to change $S_{2}$ into $S_{1}$ a state with the activity $A$ could be inserted (bold) into the third state, thereby pushing the others to "the right" (grey).

$$
\begin{aligned}
& S_{1}=(A, A, A, B, B, C) \\
& S_{2}=(A, A, \boldsymbol{A}, B, C, C, C)
\end{aligned}
$$

In a second step the $C$ in the fifth state in $S_{2}$ could be deleted (bold).

$$
\begin{aligned}
& S_{1}=(A, A, A, B, B, C) \\
& S_{2}=(A, A, A, B, C, C, C)
\end{aligned}
$$

This would move the sixth and seventh state to "the left" to fill the gap (grey).

$$
\begin{aligned}
& S_{1}=(A, A, A, B, B, C) \\
& S_{2}=(A, A, A, B, C, C)
\end{aligned}
$$

\footnotetext{
${ }^{13}$ In the approach used in this thesis activities are categorically classified. Each sequence $\left(S_{i}\right)$ is an ordered list of successive elements from the finite set of activity categories $A$. Thus $S_{i}=\left(a_{1}, a_{2}, \ldots, a_{t}\right)$ where $a_{i} \in A$ and $t$ is the number of 10 minute time steps (for a full day $t=145$ ).
} 
To complete the change of $S_{2}$ into $S_{1}$ the fifth state could be substituted, changing it from a $C$ to a $B$ (bold).

$$
\begin{aligned}
& S_{1}=(A, A, A, B, B, C) \\
& S_{2}=(A, A, A, B, B, C)
\end{aligned}
$$

There are other ways in which this could be completed, for example by using only substitution. Every inserting, deleting or substituting done in order to make a sequence into another are given a cost and the aim of the algorithm used is to minimise the total cost of changing one sequence into another.

Prior to running a sequence analysis these costs of inserting, deleting, and substitution need to be set. A study by Lesnard (2010) indicates that how costs are have an analytical effect. High cost for inserting or deleting a state will favour substitutions while low values will favour insertions/deletions (Gabadino et. al. 2011). A high degree of insertions/deletions will lead to that the change of one sequence into another is more likely to shift the timing of whereas a high degree of substitutions will retain the timing. Thus a choice has to be made between when an activity occurs (timing) and when time used and fragmentation (pattern) is similar. Sequence analysis handles these by the use of an indel (insertion/deletion) cost and substitution costs, which generally are organised in matrix form (substitution cost matrix).

The substitution cost can be set in two ways, either by the researcher or compute the substitution cost from the transition rates of the sample data. Lindmark (2010) conducted a simulation study of substitution cost that indicates that computed rates are preferable thus when applicable this is the approach used in this thesis.

Transition rate is the probability that an activity in a sequence will from one time step to another change from one activity $\left(a_{i}\right)$ to another $\left(a_{j}\right)$. More explicitly the transition rate between activity $a_{i}$ and activity $a_{j}$ is the probability of observing activity $a_{j}$ at time $t+1$ given that the state $a_{i}$ has been observed at time $t$ (Gabadinho et. al. 2010, Gabadinho et. al. 2011). The transition rate between state $s_{i}$ and $s_{j}$ is computed as follows

$$
p\left(a_{i} \mid a_{j}\right)=\frac{\sum_{t=1}^{L-1} n_{t, t+1}\left(a_{i}, a_{j}\right)}{\sum_{t=1}^{L-1} n_{t}\left(a_{i}\right)}
$$

Here $L$ is the maximal observed sequence length, $n_{t}\left(a_{i}\right)$ is the number of sequences that do not end in $t$ with activity $a_{i}$.and $n_{t, t+1}\left(a_{i}, a_{j}\right)$ is the number 
of sequences with activity $a_{i}$ at $t$ and activity $a_{j}$ at time position $t+1$. (Gabadinho et. al. 2011) For $a_{i} \neq a_{j}$, the substitution cost is equal to

$$
2-p\left(a_{i} \mid a_{j}\right)-p\left(a_{j} \mid a_{i}\right)
$$

where $p\left(a_{i} \mid a_{j}\right)$ is the transition rate between activity $a_{i}$ and $a_{j}$ (Gabadinho et. al. 2010). The inverse transition rate $p\left(a_{j} \mid a_{i}\right)$ can be computed with Bayes' theorem

$$
p\left(a_{j} \mid a_{i}\right)=\frac{p\left(a_{i} \mid a_{j}\right) p\left(a_{j}\right)}{p\left(a_{i}\right)} .
$$

When the substitution cost has been calculated for each pair of activities they can be expressed in a substitution matrix which contains the cost of substituting an activity for another. Figure 3.3 contains an example of a substitution matrix and in this example substituting activity $A$ for activity $B$ have a cost of 1.89 .

$\begin{array}{rrrr} & \mathrm{A} & \mathrm{B} & \mathrm{C} \\ \mathrm{A} & 0.00 & 1.89 & 1.91 \\ \mathrm{~B} & 1.89 & 0.00 & 1.94 \\ \mathrm{C} & 1.91 & 1.94 & 0.00\end{array}$

Figure 3.3: Example of a substitution matrix. Higher value equals to higher cost.

The cost to insert or delete a state is referred to as the Indel (insertion/deletion) cost. This is commonly set as a singular value, though a gliding, where the cost changes depending on which state is changed, indel cost can be used. Abbott and Tsay (2000) suggest using an indel cost of 1/10 of the highest substitution cost. Using the example substitution matrix in figure 3.3 this would yield a cost of 0.194 .

Broadly speaking there are two ways of computing the total cost of changing one sequence into another: Hamming distance and Levenshtein edit distance. In Hamming distance only the substitution costs are used while in Levenshtein a uses combination of insertion/deletion and substitution. The main approach in this thesis has been the use of Dynamic Hamming Distance (DHD) which differs from Hamming distance in that it uses transition rates for each time period. DHD was used in paper II and III. The choice of DHD over Levenshtein edit distance for these papers was based on the desirability of retaining the simultaneity of activities. 
The method of sequence analysis used this thesis is the version adopted in the R package TraMineR, developed by Gabadinho et al. (2011). It is based on the Needleman-Wunsch algorithm (Needleman \& Wunsch 1970).

The algorithm attempts to find the lowest cost in changing one sequence into another, either by substituting a state for another, by inserting/deleting states or via a combination of both. The sum of the costs yields for each pairing of sequences a singular value. The higher these computed costs are the less similar the sequences are; hence this value is referred to as the dissimilarity of the sequences. These dissimilarity values are collected in a dissimilarity matrix, yielding a row and column for each sequence.

The sum of the costs yields for each pairing of sequences a singular value. The higher this value is the less similar the sequence are, hence this value is referred to as the dissimilarity of the sequences. The dissimilarity values are collected in a matrix, yielding a row and column for each sequence. This value also measure the distance between two sequences, hence these matrices are referred to as distance matrices ${ }^{14}$. Figure 3.4 displays an example of a distance matrix. In this example $S_{2}$ and $S_{3}$ has a lower value (17.16) than $S_{1}$ and $S_{1}(35.91)$ meaning that the distance between $S_{2}$ and $S_{3}$ are shorter than the distance between $S_{1}$ and $S_{4}$.In essence $S_{2}$ and $S_{3}$ are less dissimilar than $S_{1}$ and $S_{4}$.

\begin{tabular}{rrrrrr} 
& \multicolumn{1}{c}{$S_{1}$} & \multicolumn{1}{c}{$S_{2}$} & \multicolumn{1}{c}{$S_{3}$} & \multicolumn{1}{c}{$S_{4}$} & $\ldots$ \\
$S_{1}$ & 0.00 & 23.14 & 24.34 & 35.91 & $\ldots$ \\
$S_{2}$ & 23.14 & 0.00 & 17.16 & 18.75 & $\ldots$ \\
$S_{3}$ & 24.34 & 17.16 & 0.00 & 19.55 & $\ldots$ \\
$S_{4}$ & 35.91 & 18.75 & 19.55 & 0.00 & $\ldots$ \\
$\ldots$ & $\ldots$ & $\ldots$ & $\ldots$ & $\ldots$ & $\ldots$
\end{tabular}

Figure 3.4: Example of a distance matrix where $S_{i}$ is an individual sequence. The higher the value, the more dissimilar the sequences are.

The computations of the sequence analysis was done in the latest available version of the statistics computing language $R$ ( $R$ Core Team 2013-2015) with the TraMineR package (Gabadinho et al. 2011).

\subsubsection{Clustering}

The sequence analysis yields a dissimilarity matrix for the analysed sequences. This dissimilarity matrix can then be used for clustering of the sequences. Clustering, or more formally cluster analysis, is an exploratory analysis. The purpose of cluster analysis is to arrange individual measurements into groups

\footnotetext{
${ }^{14}$ There are several ways of calculating distances. The method of sequence analysis (such as the Needleman-Wunsch algorithm) is one specifically aimed towards sequence data.
} 
(called clusters). The aim is to collect in one group values, objects or individuals that are more similar to one another than those included into other groups.

In the case of clustering based on sequence analysis the sequences with low dissimilarity are collected into similar groups. In this thesis the main clustering method used is an agglomerated hierarchical approach and the specific method used is Ward's minimum variance method (Ward 1963), commonly referred to as Ward's method.

Ward's method is an agglomerated hierarchical clustering method, meaning it is a "bottom up" approach where each observation starts in its own cluster and then step by step pairs of clusters are merged until all are in one cluster. (Romesburg 2004; Everitt et al. 2011) This stepwise merger can be described as a tree; it starts at the leaves and work its way towards the trunk. It looks for groups of leaves that can be formed into branches, branches that can be formed into limbs and eventually limbs formed into the trunk.

The choice of Ward's method was based in part by inspection of the resulting clusters and by the use of quality of partition measurements. Ward's method yielded both higher quality measurements compared to other methods as well as generated partitioning's that was easier to interpret. In each study the number of cluster partitioning's chosen from a combination of quality measurements of partitioning a visual inspection of the resulting clusters. Clustering was done with the cluster package (Maechler et al. 2015) in $\mathrm{R}$ (R Core Team 2013-2015) and computations of quality measurements was made with the WeightedCluster package (Studer 2013). 



\section{4 \\ RESULTS}

The result chapter will give an overview and description of the main findings and conclusions from the appended papers and will also reflect upon the finding of the thesis as a whole. Next each paper will be introduced by the respective research question to be answered and the result from each paper is presented. Thereafter the chapter will be concluded with a brief discussion on the overall results from the four papers.

The papers follow an order of thought that has been guiding throughout this thesis. The theoretical point of departure is the time-geographic approach which handles peoples' everyday lives from the perspective of what they do, in terms of timing, duration, in what sequential order and how activities are coupled to what social relevant people do. With such a point of departure it is assumed that a deep understanding of the arrangement of activities, mundane as well as unique ones, in peoples' daily life is developed. It is argued here that this also will help to better explain why changes of individuals' behaviour are so difficult to achieve.

For the purpose of this thesis, starting from investigating what activities individuals perform, when, for how long and in what sequential order, is supposed to be a more fruitful approach compared to analyse who people are in terms of socio-economic categories. Socio-economic analyses can be performed after the initial analysis of daily activity sequences and the resulting groups of similarities, in order test this assumption. For gaining knowledge about how to approach everyday life from the perspective of individuals' activity sequences, a method for investigating everyday life in an aggregated way is explored. This exploration is found in paper I, "Extracting More Knowledge from Time Diaries?" which deals with using time-diary data, sequence analysis and clustering to aggregate individuals. 
Based on the assumption that an exploration of the peoples' sequences of activities ought to lead to a better understanding how structures of everyday life affect electricity use, aggregate activity patterns were modelled through cluster analysis to show variations in domestic electricity use. This is explored in paper II, "The Impact of Individual Activity Sequences on Electrical Energy Use in the Household Sector".

Transportation, while being an important part of everyday life, is not included in the statistics of the energy use in the residential sector. The combined electricity use for domestic activities and fuels for transportation activities is explored in paper III - "Deriving Energy Use from the Context of People's Everyday Life" - wherein by using transportation sequences as basis different transportation patterns are explored.

The conclusions drawn from these three papers indicate that what activities are performed, when and in what sequence affect individuals' energy use. This leads to a question regarding peoples' possibilities to change the activities that claim electric appliances which is explored in paper IV, "Time for Change? Potential for Change and Constraints in Everyday Life". This question is relevant for policy makers who are to encourage people to conserve energy by changing behaviour as a contribution to mitigate climate change.

\subsection{Paper I: Extracting More Knowledge from Time Diaries?}

This paper is methodological to its nature as it explores the difference of using sequence analysis compared to the more traditional method of regression analysis. The results from this paper echoes in the chapter on methodological considerations (Chapter 3) as it laid the foundation for the methodological approach for the thesis as a whole.

The main finding from this paper is that using sequence analysis to analyse activities in daily life changes the logic and thereby what the analytical unit is. Some of these changes are rather noticeable whereas others are more sublime. The argument for changing the logic is that using regression relates the individuals' time use to variations in background variables. Essentially, and in accordance with this logic it is variations in the background variables that will determine the time used for various activities. In difference, the logic of sequence analysis implies that how time is used in terms of the order of the activities performed is of central importance. Rather than looking into variations in background variables this logic points towards exploring the patterns of activity sequences and identify differences there are between them. 
This leads to that the analytical unit differs between the two approaches: in regression it is the social-economic categories the individuals fall into that are central, whereas in the sequence analytical approach the sequence of activities is central. This argument on a change in logic was developed more deeply in the discussion chapter (5.2).

\subsection{Paper II: The Impact of Individual Activity Sequences on Electrical Energy Use in the Household Sector}

The second paper took its point of departure in the conclusions from the first paper and applied them to electricity use in the household. The aim and purpose of this paper was to apply sequence analysis to the electricity use of individuals from their use of appliances when performing activities within the home.

Hence, the paper examined how individuals' activity sequences could be clustered into aggregate activity patterns (clusters of activity sequences). The electricity use of these aggregate activity patterns was explored. The results from the sequence analysis yielded five different aggregate activity patterns each with its own character of activities and thus of electricity use. The timing of electricity use generated from activity sequences during the individuals' weekday in each cluster is considered.

Overall the results from this paper show that background variables have minor effects on the aggregate activity patterns. This points towards the conclusion that how days are lived, i.e. the individuals' sequences of activities have a larger impact on electricity use than how the individuals fall into categories in regards to background variables. Essentially, background variables in their own right may not be strong explanatory factors in determining the electricity use of individuals. This leads to the argument that in approaching individuals electricity use from the perspective of individuals' daily activities, what they do and in what order may matter more than how they are socio-economically classified.

A conclusion made in the paper is that information campaigns targeting households, from which the outcomes usually are poor, might yield better outcomes if they take as point of departure the individuals' pattern of activities rather than the individuals' background variables. An assumption rooted in the results is that if information on how to conserve electricity is related to activity sequences, the individuals' may have greater opportunities to recognise their own everyday situation, which may increase their capacity to act on the information. 


\subsection{Paper III: Deriving Energy Use from the Context of People's Everyday Life}

The third paper builds, as the second, upon the first paper but also some elements of the results from the second are incorporated. This paper is based in the fact that energy use from domestic activities and travel, in the debate as well as in the official energy statistics, are commonly treated as completely separate entities. However, the energy is used by individuals both for domestic activities and for travel are integrated and vital parts in the daily activity sequence of an individual. Travel enables the individual to move between geographic locations and thereby also to perform activities in geographically remote areas from the home.

As in the first two papers the focus here is sequences of activities, this time with special interest directed to patterns of travel activities, be it on foot, by bicycle, car or public transportation. The paper examines how individuals' energy use from travel can be clustered into aggregated travel activity patterns and their energy use can be accounted for. Thereby, energy use generated from domestic activities and from travel can be seen. A result from the combined energy use of activities in the home (as in paper II) and travel activities is that travel activities are a dominating part of the combined energy use. On average, of the combined energy use from activities, domestic activities consume one third while travel activities use the remaining twothirds.

A conclusion drawn from paper III is that travel is an integrated part of everyday life and ought to be regarded as such when the household sector's energy use is discussed. An important argument for this is that changes to travel patterns will affect the other activities in the sequences of activities in everyday life.

\subsection{Paper IV: Time for Change? Potential for Change and Constraints in Everyday Life}

The fourth paper takes the results and conclusions of the prior three papers as a point of departure to explore limitations and constraints for change to occur. This paper has a more theoretical and argumentative character compared to the earlier papers.

The paper argues that the activities of everyday life are not all malleable or easy to alter. Some are flexible, as the individual have a high degree of autonomy and capacity to alter the activity, whereas some are rigid, lacking autonomy making the individual's capacity to alter the activity low. A further 
argument is that alternation of an activity also means that when the activity is performed in time, for how long it endures and if it can be exchanged for another must be taken into consideration.

In the paper the empirical material is sequences of activities that have been reclassified into three different levels of flexibility: flexible, semi-flexible and rigid, where semi-flexible lies between flexible and rigid. The result shows that the activities with different levels of flexibility are scattered across the activity sequence throughout the day. This leads to the conclusion that alternations do not only affect the activity in itself but also will affect the sequence of activities of which the activity in focus for change is a part of. Essentially it means that a change of an activity cascades across the sequence of activities and thus affects a major part of, and sometimes the whole, sequence. The conclusion drawn is that in order to enable change, it is not only the particular activity to be changed that needs to be taken into consideration but rather how this change affects the sequence of activities as a whole.

\subsection{Overall results}

A theme that has been crystallised during the research process is that the activities in everyday life form a more complex context than is commonly considered. Approaching everyday life from the perspective of it being a continuous sequence of activities the interlinkage between the different, at times seemingly disparate, activities is made visible. Further, the results point towards that energy is not simply used as a consequence of an activity in which electric appliances or fuel consuming vehicles are utilised, but rather as a consequence of how these activities relate to each other in time and space by individuals in their living their daily life. The results points towards that the explanatory power of background variables in this respect may be weaker than what might be thought. A more important factor, then, is how the individuals form the sequence of activities in their everyday life.

Using sequence analysis and clustering as methods to approach everyday life offers a different kind of knowledge in line with the view of daily life as indicated above and with the theoretical framework of the time-geographic approach. Noted in paper I is that approaching time use from a sequence analysis perspective not only changes what is analysed, shifts the focus from background variables to activities, but it also changes the perspective on time. In the more traditional approaches time spent on activities are largely seen as an "expense of a time-budget" rather than a structured sequence of interdependent activities. 
In the traditional approach time use means analysing how the individuals distribute time across activities, whereas in the approach used in this thesis time use is how indivisible individuals structure their time in terms of timing, duration and sequence. Ironically the original intent behind time use surveys was to avoid the problem of seeing time use in terms of a time-budget yet the use of time use data is reduced it to time-budgets. Using sequence analysis and clustering offers a path to recapture the original intent. 


\section{5 \\ CONCLUDING DISCUSSION}

The aim of this thesis was in short to increase the knowledge about individuals' energy use as a consequence of the activities performed in everyday life. Energy use is estimated from technologies utilised when performing daily activities. The main focus of this thesis has been on sequences of activities, how they can be aggregated into activity patterns and what effect the various patterns have on energy use. The methodological approach was sequence analysis and clustering to aggregate the individual sequences into aggregate patterns of activities.

This chapter will be divided into four parts. The first (5.1) will expand upon the findings of the more applied papers, which are paper II-IV. The second part (5.2) will focus on an overall methodological discussion and thus cover paper I and the and the methodological aspects of paper II-IV. The third part will end the discussion with concluding remarks (5.3). The chapter will close with considerations for future research (5.4).

\subsection{Everyday life and energy use}

The perspective taken in this thesis is that an individual's everyday life can be regarded as a sequence of activities. Everyday life is filled with routines, habits and for the individual familiar activities. It is in everyday life that individuals realise projects they pursue for achieving goals. This daily sequence of activities forms the individual's everyday activity context. The everyday activity context focuses how the different activities performed in everyday life are linked together in time to create a cohesive everyday life.

From this perspective on everyday life energy use is not just the consequence of specific types of activities, but also of the wider context in which various types of activities are performed. It is here argued that energy 
use needs to be understood as a consequence of the everyday activity context rather than being regarded as the consequence of a certain type of activity. While the performance of an activity may be facilitated by the use of an electric appliance it is performed in conjunction with other activities. Approaching certain activities without taking the individuals' everyday activity contexts into consideration removes the contextual meaning and the function the activity serves for the individuals in the projects they pursue in order to achieve their goals.

In contemporary modern society activities commonly are related to energy use and, as indicated by the argument for the contextual approach, it should be noted that energy using activities can have the effect of enabling or disabling other activities. The assumption made in the theoretical grounding is that individuals have goals, and that these goals are realised in projects which are enacted by them performing different activities. The use of energy demanding technology when performing activities can make the attention, and thereby the time, needed by the individual to perform an activity shorter. This means that the activity will occupy a smaller part of the individual's whole sequence of activities. An example of this would be to use a dishwasher rather than washing by hand. While the time needed for the dishwasher to wash the dishes tends to be longer then for an individual to wash by hand, the time the individual has to spend for this activity is shorter. By using a dishwasher the activity of washing the dishes is performed by the technology while the individual can divert her attention and time on other activities. Hence, an activity for which appliances are used tend to occupy a shorter part of the individual's sequence of activities which makes it easier to fit the activity into the sequence of activities. In extension this means that the project of which such an activity is a part demands less attention, planning and time to carry out, giving more space for other projects and their activities to be performed. Appliances that use energy, consequently, may decouple the individual from activities with long duration. Then, the time-geographic coupling constraint is loosened, opening new spaces of opportunities for pursuing goals of other projects.

Energy demanding technology may not only occupy time in the individual's activity sequence, they may also require fewer activities to be performed to fulfil the goals of a project. Then the activities that constitute the project appear fewer times in the everyday activity context. If instead, and as might be the case without energy demanding technologies, more activities must be performed for fulfilling the project goal, these need to be fitted into the sequence of activities. When regarded in their project context these 
activities can, but must not, be directly interconnected in time. Then the fragmentation of the activity sequence increase which means that the sequence during a day has to accommodate more activities, breaking the space for other activities. Thus, a higher degree of fragmentation of the project will be the result when more activities are needed for pursuing a project, compared to using fewer but more energy demanding activities.

While the entire time used may be equal the multitude of activities fragment the sequence and the individual have to rearrange other activities in order to accommodate the higher number of episodes. Introducing or removing an energy demanding technology, hence, changes the resulting everyday activity context as well as the project context. This leads to that not only is the relation between the activities altered but also the relational meaning of the project, potentially altering the individuals perception and view of the project itself.

Energy demanding activities may in their own right use energy, but as they are parts of a sequence of activities they also affect the sequence as a whole. The various activities performed during a day are interlinked and, in the case of projects spanning over longer time periods, also linked to activities performed during other days within this period.

In any given moment the potential activities that an individual can start doing depend on the individuals' location at the now-plane, that is where the individual is located in time-space. Previous activities influence this location and have affected the activity chosen to perform at the moment and, thereby, also influence future activities. There is an important difference between previous activities, which belong to the past and can be described and analysed by using the everyday activity context and the project context concepts, and future activities, which still are in the making as the activities to be performed within various projects so far just are planned. Then, the individual's plans for future activities (related to various projects) will affect what activities the individual can perform in the moment, as the now-plane move onwards in time and space. If deeper knowledge about previous activities related to various projects in the everyday activity context is gained, it will be easier for individuals to find out how to alter activities within projects in the future in order to live a less energy intensive life.

In approaching everyday life from this perspective the core question is how the sequence of activities shape and form the everyday life. In exploring the energy use of everyday life the approach taken in this thesis is to aggregate the sequences of individuals into aggregate activity patterns.

The energy use estimated from the activity patterns has then been explored from the perspectives of domestic activities (paper II) and travel activities and 
domestic activities taken together (paper III). The results from these two papers will be discussed below, in 5.1.1 and 5.1.2 respectively. A lingering question is also the potential for change. This was the focus of paper IV and components of paper II and II. An overall discussion on the findings will be discussed in 5.1.3.

\subsubsection{Domestic activities}

The home is in many ways the nexus of everyday life. It is the locale where individuals sleep, eat, relax, and spend time with other members of the family. It is a place that has a multitude of projects associated with it and it is a place where many activities related to many projects are performed.

The energy use of domestic activities was the subject of paper II and the focus of the second research question:

2. What aggregate activity patterns can be identified from time-diaries for domestic activities and what domestic energy use can be derived from the activity patterns?

A consideration from the theoretical grounding is that the daily sequence of activities is affected by several constraints of which some require the individual to be somewhere else than in the home. Authority constrained activities, such as work and education, commonly demands the individual to spend part of the activity sequence outside the home, necessitating the individual to plan and arrange activities performed in the home from this prerequisite. The home is also a place where the capacity constraints of sleep and hunger mostly are sated. Thus, the part of the sequence of activities that occurs in the home depends on outside factors such as work and school, the need to dedicate periods of the time in the home for sleep and nourishment. Also, there are coupling constraints influencing the use of the home. For example, small children should not be left alone in the home, hence at least one adult must spend time together with the child. This can take place either in the home, or, if the adult due to authority constraints must be at a work place regularly, in a day care centre where other adults take care of the child.

The constraints act as a frame for activities in the home since the timing of when activities are performed in the home is largely a result of factors outside the individuals' control ${ }^{15}$. Earlier (5.1) the argument was presented that the activities in the everyday activity context, and consequently the sequence of

\footnotetext{
${ }^{15}$ A minor note on sleep: while the timing of sleep, i.e. bedtime and rise in the morning, can be controlled to a certain extent, the part of the sequence sleep claims is still significant.
} 
activities, throughout a day are interdependent and linked together. Taking this as a point of departure, the structure of the daily activity sequence is of relevance.

Arguably every day lived is unique, every day have something that makes it different from those before however small this difference may be. There is also commonalities between days lived. A "common" workday is in broad strokes structured as: waking up, morning routines, commute, work, commute, dinner, watching TV and bedtime. With this in mind the general structure of how days are lived can be seen as generalised everyday activity contexts, or aggregate activity patterns.

The home can be regarded as a pocket of local order since it is the locale which is arranged for the individual and organisational projects that the individuals pursue. People also keep most of their belongings in the home, belongings which shapes the layout of the home, creating the basic material structure in which life in the home is lived. Many activities are performed according to the routines of the individuals sharing a home. It is within the home as a pocket of local order that individuals carry out a variety of their activities and parts of the everyday activity context is, consequently, performed there. The way the home is ordered in terms of when what activities are performed, with what duration and together with whom, affects both the everyday activity context of individuals and how much electricity their activities in the context demands.

In paper II sequence analysis and clustering were used to create aggregate activity patterns. Following the arguments above these patterns can be seen as generalised everyday activity contexts and the energy use of each pattern can be estimated. In exploring the aggregate activity patterns it was found that the patterns have a greater impact on energy use than socioeconomic background variables. In order to address electricity use in the home, then, addressing aggregate activity patterns may be more fruitful than taking individuals' socio-economic background factors as point of departure.

\subsubsection{Travel activities}

Travel is an integral part of everyday life since not all activities are performed at the same geographical location. This makes transportation a necessary activity in order for the individual to carry out projects at different geographical locations. This section relates to the third research question, 
3. By exploring travel activities, what aggregate activity patterns can be identified and what is the combined energy use from transportation and domestic activities in daily life?

The discussion here will primarily focus on transportation as an activity. From the theoretical grounding of this thesis this can be connected to two concepts, in addition to the project context, the everyday activity context and the constraints, also the time-space prism and the geographical context.

The time-space prism is not only useful as theoretical concept to analyse the potentials for travel of individuals but also the limitations that the prism impose. On one hand the prism can be used to show the potential area that an individual can reach in a specific time using a specific speed of travel. On the other hand the potential prism of an individuals' travel activity can also be used to understand how geographical space limits the individual and the possible movements described by his or her individual path.

In order to perform activities separated in space, such as work at the workplace and dinner at home, the geographical distance needs to be overcome. This means that parts of the sequence of activities throughout a day has to be dedicated for geographical movements. Travel has an important impact on the sequence of activities as it enables the individual to perform activities, but travel may also disable activities. For example being at home enables the individual to perform activities such as cooking whereas it disables activities such as shopping and working ${ }^{16}$.

A result from paper III is that the patterns of transportation differ between geographical locations. The use of public transportation for example is dominated by individuals living in metropolitan areas. Arguable this is due to the higher access of public transportation in these areas and the higher degree of traffic congestion. This point towards the relevance of where the individual is located in geographical space, the individuals' geographical context, when the use of energy for transportation is estimated.

It is also shown in paper III that the estimated electricity use in the domestic sector (in the homes) is a minor part of the summarised energy use from transportation and electricity in the homes.

A salient point is that travel is an activity among other activities and as such it is located in the individual's sequence of activities. The arguments presented above on how activities in everyday life are interlinked and depend on other

\footnotetext{
${ }^{16}$ From the arguments presented in this thesis online shopping and telecommuting can in part be seen as activities performed to overcome the need for movement in space.
} 
activities apply here as well. Travel not only overcomes distances in space but also acts as a constraint on what activities can be performed where.

\subsubsection{The potential for change}

So far the discussion has been on patterns of energy use, with focus on how sequences of activities structures energy use in everyday life. In this part the discussion will turn towards how changing these patterns may affect energy demand and what potentials of change there is. This discussion will relate to the fourth research question:

4. By taking a time geographic approach and using sequences of activities to explore how changeable individual's everyday life is: What are the realistic opportunities for people to make changes in their everyday life?

This question was the focus of paper IV and was further brought up in parts of paper II and III. The discussion will focus on the findings of this thesis from the perspective of everyday life as an everyday activity context that is described as the uninterrupted sequence of activities.

Change in behaviour implies a change in when and for how long an activity is performed and what activity the individual performs. From the perspective of seeing everyday life as a sequence of activities this also implies that in order to change one activity there will also be a need to adjust or alter other activities in the sequence. The question is, then, what effect altering or adjusting a sequence of activities may give rise to.

In order to change an activity the individual must have the potential for change. Some activities are constrained by authorities, such as work, and are not possible for the individual to effect. In order for the individual to be able to rearrange an activity there must be a degree of flexibility connected with the activity. The flexibility of everyday life is the subject of paper IV and it asks the question of how malleable everyday life is. The finding initially shown in the paper is that the potential for change of everyday life is on average high in terms of how much time is flexible. The findings show that on average around 40 per cent of the time during weekdays and 50 per cent during weekends have a degree of potential for change. However these aggregated proportions do not take into account neither the timing nor the duration of the activities, for example how this potential for change in activities is distributed throughout the day. Taking into consideration that the activities are performed as a part of the sequence revealed by the everyday activity context, will give a different result concerning how flexible the activities are. The findings points 
towards that the day shifts from flexible to rigid and long periods of flexibility are scarce. This further points towards that rearranging a day to accommodate for a change in an activity is rather limited.

There is however also another consequence of altering or adjusting the sequence of everyday life. If everyday life is regarded as a sequence of activities this also means that moving an activity in time, changing its duration or changing how it is performed will change the sequence itself. From this follows that it is not only whether a particular activity can be altered or adjusted that matters but also how this change affects other activities of the sequence.

A fundamental assumption in this thesis is that the activities individuals perform are part of projects. Projects are driven by the goals of the individual, which indicate that the desires, dreams, hopes and demands of the individual have an effect on what projects the individual pursuit. In order to enact a change in a project, consequently, the activities of the project will be affected as well. Following the argument that changes to an activity affects the sequence this implies that a change in the activities of a project interfere with other projects since the projects are interweaved in the everyday activity context.

Change to a singular activity can ripple across the sequence, thus affecting other activities and impact other projects unrelated to the project containing the changed activity. This means that in order to accommodate change it must be possible for the individual to find a solution where the effect of the change across multiple projects is acceptable.

Taken together a project and its associated activities may be malleable, however, due to the effect a change within a project can have on other, less malleable projects, may lead to that the change does not occur. While the individual may feel a demand or have a desire to perform a project in one way, the effect of changing this project has on other projects may prohibit the change to occur. Essentially the effect changes has on other activities and projects may act as a limitation on change.

A further complication is that some projects in the home are organisational projects, shared between the members of the household. The consequence of this is that change to an individual activity may not only impact the projects of this individual but also the projects that the individual share with other members of the household. This means that a change in one activity that has an effect on the participation in a shared project will also have an effect on the sequences of activities of the other household members. A change, then, may 
not only ripple across the individual's own activity sequence and projects but also cascade across the projects of other members of the household.

A final point concerns the home itself. From the perspective of the home as a pocket of local order changes to the sequence of activities may necessitate a reordering of the pocket. This may act as another limitation for the change to occur. Changing the order of the home have an effect on other projects the individual and other members of the household pursued within this pocket of local order.

In conclusion, a small change might be small as such but the consequences of enacting such a minor change may very well be large. In order for change of an activity to occur the change will have to fit into an interlinked context of individual activities, individual and shared projects, and the order of their home. When changes in individuals' activities are urged for energy conservation reasons, there are many interdependencies and contexts to take in consideration if the change aimed at also will be realised.

\subsection{Sequence analysis and clustering as a methodological approach}

The main methodological approaches used in this thesis are sequence analysis and clustering. This part will discuss using sequence analysis and clustering on time-diary data and relate to the first research question:

1. How can individuals' activity sequences from time-diaries on an aggregated level be used to explore everyday life that gives more knowledge than studies not taking the sequence into consideration?

This research question was approached by exploring and comparing two methods of analysing time-diary data, regression modelling and sequence analysis. This was the focus of paper I and the finding of this paper have further been discussed in the methodological chapter (3) and the discussion (5.2). The main conclusion is that by using aggregate sequences of activities a different perspective on everyday life and time use emerges. Then everyday life is regarded as a coherent whole and the resulting aggregate patterns can be utilised to gain a better understanding of how everyday life is lived.

The fundamental assumption made in this thesis is that activities that individuals perform are interlinked in everyday life and taken together they form a cohesive, and for the individual, meaningful whole. Activities are assumed to be performed by an individual as parts of various projects and 
together they constitute the individual's everyday activity context. Further, it is assumed that the home, regarded as a pocket of local order, is an important locale for performing activities, and that the individual's performance of activities is limited by constraints. The sequence that the performed activities give rise is to be regarded as the outcome of the individual's realisation of her pursuing projects. From these assumptions the primary analytical unit ought to be the activity sequence rather than background factors such as age and gender. This calls for a change in the analytical logic.

An argument for this statement is that background variables matters in the sense that they have an effect on which projects individuals' pursuit rather than what specific activities they perform. Projects are motivated by the dreams, hopes and goals of the individual and arguably there are differences between individuals in these regards that have a source in background variables, attitudes and life experiences. The effect of these sources on the activities performed is that they influence both what projects individual pursue and the how important projects are perceived to be. This in turn affects how projects are realised, how they are prioritised and thus it guides the formation of the sequence of activities that an individual performs. From this perspective the sequence analytical perspective reveals the activity pattern of everyday life whereas more traditional methods such as regression analysis would help in identifying different projects.

Sequence analysis method is regarded as suitable for the approach in this thesis. The method takes into account the duration, timing, frequency and order of activities. This means that not only what activity is performed when and for how long, is considered but also the number of and the order of the episodes performed are retained from the time-diary data. By using algorithms to explore the dissimilarities between sequences and these dissimilarities can be used to aggregate the sequences into clusters yielding generalised patterns. These patterns are not "real" days, however their character can be interpreted as representations of typical, or common, days. These patterns, or typical days, can then be analysed with statistical methods to explore their composition of background variables.

This implies a change in the logic of analysing time use compared to methods such as regression modelling. Since sequence analysis is based on the sequences of activities it does not in its application take into account the individual socioeconomic factors. This means that individuals by this method are analysed from what they do rather than who they are in terms of background variables. The main difference in logic is that in regression modelling the background variables stands as explanatory to the activities 
performed by individuals and aim to discover how variations in background variables affect time use. In the sequence analysis approach the individuals' activities are explored and the method aims to discover differences in patterns of activities. For this sake clusters are produced, resulting in aggregate activity patterns. These patterns differ from each other while the activity sequences within each one are similar. Background variables in sequence analysis are then used to explore the composition of the individuals in each aggregate activity pattern.

The results from paper I is a demonstration of the difference in logic. On one hand, in comparing the time spent in paid work between men and women with regression analysis a difference between the genders can be found and the effect of the difference can be estimated. On the other hand, by applying sequence analysis different aggregate patterns of paid work in peoples' daily life were extracted. The patterns revealed three distinctly different clusters of paid work days: no work, part time work and fulltime work days. By exploring these aggregate work patterns in regards to gender the results show that there are notable differences between the genders in what pattern is dominant. The regression analysis thus signifies that there is a gender difference but the sequence analysis gives a descriptive difference in how the genders differ. In conclusion, the difference is that the regression approach reveals that men generally work longer than women, whereas the sequence analysis approach reveals that the patterns of work differ among both men and women when it comes to timing and duration of work activities.

Another result that more clearly points towards the change in logic is from paper II was that each cluster has its own character when explored with background variables, for example gender differences were found, but only in two out of five patterns.

In closing, the sequence analytical approach changes what is being analysed and offers a way to explore everyday life that focus the activities as constituents of a consistent whole where they eventually follow upon each other, giving a more holistic perspective on everyday life. As such it is a strong complement to more traditional methods such as regression. Using sequence analysis and regression in conjunction seems to be a promising way to further deepen the understanding of everyday life and how energy is being used.

\subsection{Concluding remarks}

In trying to enact change in order to reduce energy consumption the effects, if regarded from the perspective of an individual's activity sequence, will not only be on the specific activity targeted, but the change will have an indirect 
impact on other projects and thereby upon the goals of the individual. Thus in changing an activity to be less energy demanding there will be a negotiation about the goal to use less energy and the goals of other projects. While energy is used in performing activities to further projects, a feature of energy use is that it also helps to structure the everyday activity context, as well as to overcome and handle constraints.

Contemporary society is largely structured towards certain periods of work (authority constrained activities), sleep (this one being a capacity constrained activity) and other activities. This "rhythm" also shapes the structure within which the everyday activity context is realised. The shaping of the structure of everyday life affects what projects an individual can engage in. It is also within in this frame that the individual interacts (the social context) and coordinates (coupling constrains) with socially important others in different environments (the geographical context).

Facilitate change means affecting this intricate web of interaction and interdependent activities in the daily activity sequence. Then the focus in policy information campaigns addressing energy conservation ought to be based on how everyday life contexts are shaped and formed both by societal structures and by negotiations between individuals in households. If so, they

can build upon better knowledge about what constraints act upon the individuals' activities, how they are interlinked and what effects changes to these will yield. The method to cluster activity sequences presented in this thesis may serve as a starting point in changing information campaigns in this direction.

\subsection{Considerations for future research}

The energy use of households have in this thesis been approached from an individual perspective, however households are generally consisting of multiple individuals who share responsibilities and goals with the projects performed in the home.

An issue here is that there is a lack of quantitative methods that can handle the interactions of multiple individuals. The combined energy use of the activities of the household can be analysed or measured but in these approaches the particulars of the individuals are either not included, or added to the analysis, commonly linear models, as covariates.

Thus the interaction, the coupling constraints impeding upon everyday life, is rarely touched upon. There is a need for a quantitate model to analyse the interactions of individuals and how they together form the households everyday life contexts. 
Further, analysing the activities of everyday life would benefit from the possibility to model interactions and shared activities in order to deeper explore how the constraints, projects and contexts of everyday life limits or enables changes. It will also underline the vital couplings between individuals that make everyday life social.

Another outcome of this thesis is the argument that attitudes, values and perspectives are not directly linked to activities; rather attitudes are linked to projects and in enacting the projects activities are performed. This connection would be valuable to explore in order to deepen the understanding of how the attitude, values and perspective when realised in projects compete and how individuals find a balance between these projects in their behaviour. 



\section{6 \\ SUMMARY}

This thesis is a contribution to the knowledge development concerning energy conservation in households in order to mitigate climate change. The aim is to increase the knowledge about aggregate energy use among individuals in Sweden by exploring their activities performed in everyday life. The everyday perspective focuses the individuals' sequences of activities and how these affect energy use. An overall purpose is to explore the energy use and the potential for energy conservation of individuals' with different activity patterns so policy information campaigns can be formulated to better reach targets groups defined by similarities according to activity sequence.

Four research questions are posed with the first starting in methodological considerations:

1. How can individuals' activity sequences from time-diaries on an aggregated level be used to explore everyday life that gives more knowledge than studies not taking the sequence into consideration?

The results from this first step laid the path for the second and third research question:

2. What aggregate activity patterns can be identified from time-diaries for domestic activities and what domestic energy use can be derived from the activity patterns?

3. By exploring travel activities, what aggregate activity patterns can be identified and what is the combined energy use from transportation and domestic activities in daily life?

A theme that was returning during the exploration of these research questions lead to the fourth and final research question:

4. By taking a time geographic approach and using sequences of activities to explore how changeable individual's everyday life is: What are the realistic opportunities for people to make changes in their everyday life? 
The theoretical grounding is the time-geographical approach. The choice is motivated by that time-geography takes its point of departure in the indivisibility of the individual as the individual pursue actions through space and time. It offers a framework for analysing how the activities in their unbroken sequence together form everyday life and also set the activities into contexts.

The time-geographic concepts used in the thesis relate to the sequence of activities performed by individuals in living an everyday life. The everyday activity context reveals the individual activity sequence in the course of the day. The activities performed throughout a day give meaning to the individual since they are constituents of projects for which the individual has a goal. Constraints (capacity, authority and coupling constraints) are used in analysing the limitations for the individual's opportunities to realise activities, and they thereby also restrict her possibilities to achieve the project goal, in their everyday life. The concept of projects enables a perspective where diverse activities performed by individuals constitute a meaningful whole. Project contexts indicate a relational meaning of various interlinked activities, however dispersed in time and space. Travel is an integrated part of everyday life and the concept of time-space prism aids analysing the potentials and limitations that geographical distances and the efforts to overcome these pose for individual in realising an everyday life.

In order to empirically investigate individuals' activity sequences there is a need for data that includes a time dimension related to everyday activities and methods that allow analysis of the activity sequences related to indivisible individuals. Time use diaries collected in 2010/2011 in the Swedish time use survey performed by Statistics Sweden are utilised. They provide unbroken individual activity sequences. Sequence analysis and clustering have been employed for grouping the sample individuals with similar activity sequences together to form aggregate activity patterns.

To the thesis four papers are attached. Each of them relate to one research question. Paper I "Extracting More Knowledge from Time Diaries?" refers to research question 1 and the result is that in analytically approaching the activities of everyday life from the perspective of a sequence of activities rather than as separate entities yields a more nuanced picture. This approach changes the logic and puts a higher emphasis on the activities of indivisible individuals compared to methods such as regression modelling.

Paper II "The impact of individual activity sequences on electricity energy use in the household sector" refers to research question 2 and the paper shows that background variables have minor effects on the aggregate activity 
patterns. This point towards individuals' sequences of activities has a larger impact on electricity use than the background variables of individuals.

Paper III "Deriving energy use from the context of peoples' everyday lives - a study of domestic and travel activities" refers to research question 3 and the paper demonstrate that the activity of travel is an integrated part of the everyday activity context and, consequently, an activity among other activities. As such changes to travel patterns will affect other activities in the sequences of activities in everyday life. Travel activities use more energy than the domestic activities which urges measures to be taken to reduce energy use from fossil fuelled vehicles.

Paper IV "Time for Change? Potential for Change and Constraints in Everyday Life" refers to research question 4 and the paper shows that the activities in the everyday activity context are not all easy to alter. The degree of autonomy and capacity to alter the activity are scattered across the sequence of activities, and alternations do not only affect the activity in itself but also will affect the sequence of activities. Altering an activity will impact not only the individual herself, but also other individuals in the household.

In the discussion chapter the difference between the sequence analytical approach utilised in this thesis and conventional regression analysis is scrutinised more in depth. The methodological approaches, sequence analysis and clustering, shifts the focus from background variables to the sequence of activities, giving a more holistic perspective on everyday life. As such it is a strong complement to more traditional methods such as regression in exploring everyday life.

The conclusion drawn from the overall research in this thesis is that in attempts to enact change to reduce energy consumption the effects, if regarded from the perspective of an individual's activity sequence, will not only be on the specific activity targeted. The change will have an indirect impact on other projects and thereby upon the goals of the individual. In changing an activity to be less energy demanding there will be a negotiation about the goal to use less energy and the goals of other projects. While energy is used in performing activities to further projects, a feature of energy use is that it also helps to contextualise and structure everyday life, as well as to overcome and handle constraints.

As a consequence, change affects the intricate web of interdependent activities in the daily activity sequence. From this springs that the focus in policy information campaigns that are directed towards energy conservation should be based on how everyday life contexts are shaped and formed both by societal structures and by negotiations between individuals in households. 
Chapter 6

This thesis can for policy makers serve as an basis for an approach on how to target information about energy conservation to individuals' with different activity patterns. 


\section{REFERENCES}

Abbott, A. (1983). Sequences of social events. Historical Methods, 1 (4)

Abbott, A. (1990). A primer on sequence methods. Organization Science, 1

Abbott, A. (1995). Sequence analysis: New methods for old ideas. Annual Review of Sociology, 21

Abbott, A. \& A. Hrycak (1990). 'Measuring Resemblance in Sequence Analysis: An Optimal Matching Analysis of Musicians' Careers', American Journal of Sociology, 96

Abbott, A., \& Tsay, A. (2000). Sequence analysis and optimal matching in sociology: Review and prospects. Sociological Methods \& Research, 29

Aune, M (1998). Nøktern eller Nytende. Energiforbruk og hverdagsliv i Norske husholdninger, Phd dissertation, STS-report 34. Center for technology and society, NTNU

Aune, M. (2007). Energy comes home. Energy Policy, 35

Beck, M. E. \& Arnold, J. E. (2009). Gendered time use at home: an ethnographic examination of leisure time in middle-class families. Leisure Studies 28 (2)

Bejerholm, U. \& Eklund, M. (2006). Engagement in occupations among men and women with schizophrenia. Occupational Therapy International 13(2)

Bennich, P. (2007). Mätning av hushållsel i 400 bostäder. Presentation at Energitinget, 2007

Berker, T. (2013). "In the morning I just need a long, hot shower:" a sociological exploration of energy sensibilities in Norwegian bathrooms. Sustainability: Science, Practice, \& Policy, 9 (1)

Bianchi, S. \& Robinson, J. (1997). What did you do today? Children's use of time, family composition, and the acquisition of social capital. Journal of Marriage and Family, 2

Billari, F.C. \& Piccarreta, R. ( 2005). 'Analyzing Demographic Life Courses through Sequence Analysis.' Mathematical Population Studies, 12

Bonke, J. (2005). Paid work and unpaid work: Diary information versus questionnaire information. Social Indicators Research, 70

Boone, J., Sadreih, A. \& van Ours, J. (2009). Experiments on unemployment benefit sanctions and job search behaviour. European Economic Review, 53

Brown, J., Broom, D., Nicholson, J. \& Bittman, M. (2010). Do working mothers raise couch potato kids? Maternal employment and children's lifestyle behaviours and weight in early childhood. Social Science and Medicine, 70

Carlsson-Kanyama, A. \& Lindén, A-L. (2007). Energy efficiency in residences - Challenges for women and men in the North. Energy Policy, 35 (4) 


\section{References}

Carlstein, T. (1980). Time, Resources, Society and Ecology. Doctoral thesis, Lund University, Lund, Sweden

Castells, M. (2000). The Rise of the Network Society. Routledge.

Chen, J., Shaw, S-L., Yu, H., Lu, F., Chai, Y. \& Jia, Q. (2011). Exploratory data analysis of activity diary data: a space-time GIS approach, Journal of Transport Geography, 19(3)

Claessens, B. J. C., van Eered, W., Rutte, C. G., \& Roe, R. A. (2010). Things to do today...: A daily diary study on task completion at work. Applied Psychology, 59(2)

Cohen, J. D. (2011). A Time-diary Study of Adult Everyday Writing Behavior. Written Communication, 28 (1)

Druckman, A \& Jackson, T (2008). Household energy consumption in the UK: A highly geographically and socio-economically disaggregated model. Energy Policy, 36

Ellegård, K. (1994). Att fånga det förgängliga: Utveckling av en metod för studier av vardagslivets skeenden [Capturing the perishable: Development of a method for studies of the course of events of everyday life]. Occasional Papers 1994:1. Department of Human and Economic Geography, School of Economics and Commercial Law Gothenburg, Sweden: Gothenburg University

Ellegård, K. (1994b). Vardaglivets komposition. [The composition of daily life over time]. Goteborg: Department of Human and Economic Geography, Goteborg University

Ellegård, K. (1999). A time-geographical approach to the study of everyday life of individuals - a challenge of complexity. GeoJournal, 48(3)

Ellegård, K. (2006). The power of categorisation in the study of everyday life. Journal of Occupational Science, 13

Ellegård, K. \& Palm, J. (2011). Visualizing energy consumption activities as a tool for making everyday life more sustainable, Applied Energy, 88 (5)

Ellegård, K. \& Vilhelmson, B.(2004). Home as a pocket of local order: Everyday activities and the friction of distance. Geografiska Annaler, 86 B (4)

Ellegård, K. (1993). Olikadant. Aspekter på tidsanvändningens mångfald, Occasional Papers 1993:4. Kulturgeografiska institutionen, Göteborgs universitet

European Commission (2015). Europe 2020, [online] http://ec.europa.eu/europe2020/index_en.htm, retrieved 2015-03-15

European Energy Agency (2014). Greenhouse Gas Emissions Dataset: env_air_gge, retrived 2015-06-16

European Environmental Agency (2105a). Energy consumption by end use per dwelling, 2009 [online] http://www.eea.europa.eu/data-and-maps/figures/households-energy-consumptionby-end-uses-5 Retrieved 2015-09-18

European Environmental Agency (2105b). Energy consumption by transport mode in the EU-27 [online] http://www.eea.europa.eu/data-and-maps/figures/consumption-by-mode-eu-2 Retrieved 2015-09-18

Eurostat (2009). Harmonised European time use surveys 2008 guidelines, Eurostat Methodologies and Working papers, product code: KS-RA-08-014

Eurostat (2015a). Final energy consumption by sector [online] http://ec.europa.eu/eurostat [table] tsdpc320, retrieved 2015-03-15

Eurostat (2015b). Energy from renewable sources [online] http://ec.europa.eu/eurostat/statistics-explained/index.php/Energy_from_renewable_sources Retrieved 2015-09-17

Eurostat (2015c). Final energy consumption in households by fuel [online] http://ec.europa.eu/eurostat [table] t2020_rk210, retrieved 2015-03-15 
Everitt, B.S., Landau, S., Leese, M. \& Stahl, D. (2011). Cluster Analysis (5th ed.), Chichester: Wiley

Fisher, K., Bennett, M., Tucker, J., Altintas, E., Jahandar, A., Jun, J., and other members of the Time Use Team (2009). Time use studies. http://www-2009.timeuse.org/information/studies/. retrieved 2013-03-15

Friberg, T. (1991). Kvinnors vardag. Om kvinnors arbete och liv. Anpassningstrategier i tid och rum. Doctoral thesis, Lund University, Lund, Sweden

Gabadinho, A., Ritschard, G., Müller, N. S., \& Studer, M. (2011). Analyzing and visualizing state sequences in $\mathrm{R}$ with TraMineR. Journal of Statistical Software, 40 (4)

Gabadinho, A., Ritschard, G., Studer, M. \& Muller, N. S. (2010). Mining sequence data in $R$ with the TraMineR package: A user's guide University of Geneva

Gershuny, J. (2011). Time-use surveys and the measurment of national well-being. Office for National Statistics, Lindo, UK

Gershuny, J. Time Use Research Methods, in: Baltes, P. und N. Smelser (Eds), (2001). International Encyclopedia of the Social \& Behavioral Sciences, Elsevier Science Limited, Amsterdam

Gershuny „, J. \& O. Sullivan (1998). The Sociological Uses of Time-Use Diary Analysis. European Sociological Review, 14(1)

Giddens, A. (1979). Central Problems in Social Theory: Action, Structure, and Contradiction in Social Analysis, Oakland: University of California Press

Giddens, A. (1986). The Constitution of Society: Outline of the Theory of Structuration (New Ed Edition). Oakland: University of California Press

Giddens, A. (1991). Modernity and self-identity. Cambridge: Polity Press

Gram-Hansen, K. (2003). Boligers energiforbrug - sociale og tekniska forklaringen på forskelle. Rapport 029, By og BYG. Statens Byggeforskningsinstitut, Hörsholm

Gram-Hansen, K. (2008). Heat comfort and practice theory: understanding everyday routines of energy consumption. In Proceedings: Referred Sessions I-II. Sustainable Consumption and Production: Framework for Action: 2nd Conference of the Sustainable Consumption Research Exchange Network.

Hallin, P-O. (1988). Tid för omställning: om hushålls anpassningsstrategier vid en förändrad energisituation. Doctoral thesis, Lund University, Lund, Sweden

Hamming, R. W. (1950). Error detecting and error correcting codes. Bell System Technical Journal, $29(2)$

Harms, T. \& Gershuny, J. (2009). Time Budgets and Time Use, German Council for Social and Economic Data Working Paper No. 45, Berlin

Harvey, A. (1993) Guidelines for time-use collection. Social Indicators Research, 30

Harvey, A. \& Niemi, I. (1994). An International Standard Activity Classification (ISAC): towards a framework, relevant issues. In Fifteenth Meeting of the International Association for Time Use Research, Amsterdam June 1993.

Harvey, D. (1990). The condition of Postmodernity: an Enquiry into the origins of Cultural Change. Wiley-Blackwell.

Hägerstrand, T. (1983). Det energisnåla samhället. In Carlestam, G. \& Sollbe, B. (eds) Om tidens vidd och tingens ordning. Byggforskningsrådet T21:1991

Hägerstrand, T. (1970). What about people in regional science? Papers in Regional Science, 24(1)

Hägerstrand, T. (1973). The domain of human geography. In Richard J. Chorley, Directions in geography. London: Methuen

Hägerstrand, T. (1974). Tidsgeografisk beskrivning: Syfte och postulat. Svensk Geografisk Årsbok 1974 


\section{References}

Hägerstrand, T. (1975). Space, time and human conditions. In Karlqvist, A., Lundqvist, L., Snickars, F. (eds) Dynamic allocation of urban space. Lexington, MA: Lexington Books

Hägerstrand, T. (1982). Diorama, path and project, Tijdschrift voor Economische en Sociale Geografie, 73

Hägerstrand, T. (1985). Time geography: focus on the corporeality of man, society and environment. In Aida, S. The science and praxis of complexity: contributions to the symposium held at Montpellier, France, 9-11 May, 1984. Tokyo: United Nations University Press.

Hägerstrand, T. (1989). Reflections on 'what about people in regional science? Papers in Regional Science, 66(1)

Hägerstrand, T. (2009). Tillvaroväven, Formas

International Energy Agency [IEA] (2012). World Energy Outlook 2012.

International Energy Agency [IEA] (2014a). CO2 Emissions from Fuel Combustion Highlights 2014

International Energy Agency [IEA] (2014b). Energy Supply Security: The Emergency Response of IEA Countries - 2014 Edition OECD: Paris

International Energy Agency [IEA] (2015) IEA total, Final Consumption 2012, [online] http://www.iea.org/Sankey/index.html\#?c=IEA\%20Total\&s=Final\%20consumption, retrieved 2015-05-01

Intergovernmental Panel on Climate Change [IPCC] (2013). Climate Change 2013: The Physical Science Basis. Contribution of Working Group I to the Fifth Assessment Report of the Intergovernmental Panel on Climate Change [Stocker, T.F., D. Qin, G.-K. Plattner, M. Tignor, S.K. Allen, J. Boschung, A. Nauels, Y. Xia, V. Bex and P.M. Midgley (eds.)]. Cambridge University Press, Cambridge, United Kingdom and New York, NY, USA

Isaksson, C. (2009). Uthålligt lärande om värmen? Domesticering av energiteknik i passivhus. PhD dissertation, Linköping University, Sweden

Juster, F. T., Ono, H., \& Stafford, F. P. (2003). An assessment of alternative measures of time use. Sociological Methodology, 33

Kan, M. Y. (2008). Measuring housework participation: The gap between 'stylised' questionnaire estimates and diary-based estimates. Social Indicators Research, 3

Kan, M. Y. \& Pudney, S. (2008). Measurement error in stylized and diary data on time use. Sociological Methodology, 38

Karresand, H. (2014). Apparater, aktiviteter och aktörer: Lågenergiboende som resurs och restriktion för energiordningar. PhD dissertation, Linköping University, Sweden

Karlsson, K \& Widén, J (2008). Hushållens elanvändningsmönster identifierade i vardagens aktiviteter. Tema T Arbetsnotat, Linköpings universitet

Krantz, H. (2005). Matter that matters. A study of household routines in a process of changing water and sanitation arrangements. PhD dissertation, Linköping University, Sweden

Krantz, H. (2012). Water Systems Meeting Everyday Life: A Conceptual Model of Household Use of Urban Water and Sanitation Systems. Public Works Management \& Policy 17 (1)

Kroksmark, U., Nordell, K., Bendixen, H.J., Magnus, E., Jakobsen, K \& Alsaker, S. (2006). Time Geographic Method: Application to Studying Patterns of Occupation in Different Contexts. Journal of Occupational Science, 13:1

Krueger, A. B. \& Mueller, A. (2010). Job search and unemployment insurance: New evidence from time use data. Journal of public Economics, 94

Kwan, M-P. (1998). Space-time and Integral Measures of Individual Accessibility: A Comparative Analysis using a Point-based Framework. Geographical Analysis, 30 (3)

Kwan, M-P. (2001). Cyberspatial cognition and individual access to information: The behavioral foundation of cybergeography. Environment and Planning B, 28 
Kwan, M-P. (2002). Time, information technologies and the geographies of everyday life. Urban Geography, 23 (5)

Le Quéré, C., A. K. Jain, M. R. Raupach, J. Schwinger, S. Sitch, B. D. Stocker, N. Viovy, S. Zaehle, C. Huntingford, P. Friedlingstein, R. J. Andres, T. Boden, C. Jourdain, T. Conway, R. A. Houghton, J. I. House, G. Marland, G. P. Peters, G. Van Der Werf, A. Ahlström, R. M. Andrew, L. Bopp, J. G. Canadell, E. Kato, P. Ciais, S. C. Doney, C. Enright, N. Zeng, R. F. Keeling, K. Klein Goldewijk, S. Levis, P. Levy, M. Lomas, \& B. Poulter. (2012). The global carbon budget 1959-2011. Earth System Science Data Discussions 5, no. 2

Lenntorp, B. (1976). Paths in Space-Time Environments: A Time Geographic Study of Movements of Individuals. Lund Studies in Geography, 44, Royal University of Lund, Sweden

Lenntorp, B. (1999). Time-geography - at the end of its beginning. GeoJournal, 48 (3)

Lenntorp, B. (2005). Path, Prism, Project, Pocket and Population: An Introduction Geografiska Annaler Series B Human Geography, 86(4)

Levenshtein, V. I. (1966). Binary codes capable of correcting deletions, insertions, and reversals. Soviet Physics Doklady, 10 (8)

Lindén, A-L. (2008). Hushålsel energieffektivisering i vardagen, Research Report 2008:5, Department of Sociology, Lund University

Maechler, M., Rousseeuw, P., Struyf, A., Hubert, M., \& Hornik, K. (2015). cluster: Cluster Analysis Basics and Extensions. R package version 2.0.3.

Michelson, W. Analysis and Exploration of meaning and Outcomes in Connection with Time Use Data, In Pentland, W. E., Lawton, M. P., \& Harvey, A. (Eds.). (1999). Application of Time Use Methodology in the Social Sciences. Hingham, MA, USA: Kluwer Academic Publishers.

Miller, H.J. (1991). Modelling accessibility using space-time prism concepts within geographical information systems. International Journal of Geographical Information Systems, 5(3)

Miller, H.J. (2004). Activities in space and time. In Hensher, D.A., Button, K.J., Haynes, K.E., \& Stopher, P.R. (eds) Handbook of Transport Geography and Spatial Systems, Oxford: Elsevier

Miller, H.J. (2005). A Measurement Theory for Time Geography. Geographical Analysis, 37

Millward, H. \& Spinney, J. (2011). "Active living" related to the rural-urban continuum: A timeuse perspective. The Journal of Rural Health, 27

Motiram, S. \& Osberg, L. (2009). Gender inequalities in tasks and instruction opportunities within Indian families. Feminist Economics, 16(3)

Nordell, K. (2002). Kvinnors hälsa - en fråga om medvetenhet, möjligheter och makt: att öka förståelsen för människors livssammanhang genom tidsgeografisk analys, Doctoral thesis, School of Business, Economics and Law, Gothenburg University, Gothenburg, Sweden

Otterbach, S. \& Sousa-Poza, A. (2010). How accurate are German work-time data? A comparison of time-diary reports and stylized estimates. Social Indicators Research, 97

Palm, J. \& Darby, S. (2014). The meanings of practices for energy consumption - a comparison of homes and workplaces. Science \& Technology Studies, 27(2)

Pentland, W.E. Harvey, A.S., Lawton, M.P., \& McColl, M.A. (1999). Time use research in the social sciences New York: Springer US

Poortinga, W., Steg, L., Vlek, C., \& Wiersma, G. (2003) Household preferences for energy saving measures: A conjoint analysis. Journal of Economic Psychology, 24

Powells, G., Bulkeley, H., Bell, S., \& Judson, E. (2014). Peak electricity demand and the flexibility of everyday life. Geoforum, 55

Pred, A. (1981) Social Reproduction and the Time-Geography of Everyday Life. Geografiska Annaler. Series B, Human Geography, 63 (1) 


\section{References}

Pred, A. (1985). Presidential address interpenetrating processes: Human agency and the becoming of regional spatial and social structures. Papers in Regional Science, 57 (1)

R Core Team (2012-2015). R: A Language and Environment for Statistical Computing. R Foundation for Statistical Computing, Vienna, Austria

Ricci, J., Jerome, N., Megally, N., Galal, O., Harrison, G., \& Kirksey, A. (1995). Assessing the validity of information recall: Results of a time use pilot study in peri-urban Egypt. Human Organization, 54

Robinson, J. P. \& Gershuny, J. (1994). Measuring hours of paid work: Time-diary vs. estimate questions. Bulletin of Labour Statistics, 11-17.

Robinson, J., Martin, S., Glorieux, I., \& Minnen, J. (2011). The overestimated workweek revisted. Monthly Labor Review, June 2011.

Romesburg, C. (2004). Cluster Analysis for Researchers, Raleigh: Lulu.com

Schneider, D. (2011). Market earnings and household work: New tests of gender performance theory. Journal of Marriage and Family, 73

Semenza, J., Hall, D., Wilson, D., Bontempo, B., Sailor, D., \& George, L. (2008). Public perception of climate change: Voluntary mitigation and barriers to behaviour change, American Journal of Preventive Medicine, 35 (5)

Shaw, S. L. (2006). What about "time" in transportation geography?. Journal of Transport Geography, 14(3)

Shaw, S. L., \& Yu, H. (2009). A GIS-based time-geographic approach of studying individual activities and interactions in a hybrid physical-virtual space. Journal of Transport Geography, $17(2)$

Shove, E (2003). Comfort, cleanliness and convenience. New technologies/new cultures series. Oxford

Shove, E (2007). The design of everyday life. Cultures of consumption series. New York

Spaargaren, G. (2003). Sustainable Consumption: A Theoretical and Environmental Policy Perspective. Society and Natural Resources, 16

Spinney, J. E. L., Millward, H., \& Scott, D. M. (2011). Measuring active living in Canada: A timeuse perspective. Social Science Research, 40

Statistics Sweden (2013). Nu för tiden. En undersökning om svenska folkets tidsanvändning år 2010/11. Stockholm: Statistics Sweden

Statistics Sweden (2015). Tillförsel och användning av el 2001-2013 (GWh) [online] http://www.scb.se/sv_/Hitta-statistik/Statistik-efter-amne/Energi/Tillforsel-och-anvandningav-energi/Arlig-energistatistik-el-gas-och-fjarrvarme/6314/6321/24270/\# Retrieved 2015-04-18

Steg, L. \& Gifford, R. (2005). Sustainable transportation and quality of life. Journal of Transport Geography, 13

Strengers, Y. (2013). Smart Energy Technologies in Everyday Life. Smart Utopia? London: Palgrave Macmillan

Strengers, Y., Maller, C. \& Nicholls, L. (2014) Curious energy consumers: Humans and nonhumans in assemblages of household practice Journal of Consumer Culture [vol. online]

Studer, M., Ritschard, G., Gabadinho, A., \& Müller, N. S. (2011). Discrepancy analysis of state sequences. Sociological Methods \& Research, 40

Studer, Matthias (2013). WeightedCluster Library Manual: A practical guide to creating typologies of trajectories in the social sciences with R. LIVES Working Papers, 24.

Sullivan, O. \& Gershuny, J. (2001). Cross-national changes in time-use: some sociological (hi)stories re-examined. British Journal of Sociology 52(2)

Swedish Energy Agency (2008). Energiläget 2008 [report] Energimyndigheten ER2008:15 
Swedish Energy Agency (2014). Energiindikatorer 2014 [report] Energimyndigheten ER2014:10 Swedish Energy Agency (2015). Energiindikatorer 2015 [report] Energimyndigheten ER2015:15 Szalai, A. (eds) (1972). The use of time: Daily activities of urban and suburban populations in twelve countries. Den Haag, Netherlands: Mouton \& Co.

United Nations Statistics Division (2015a). Trial ICATUS, [online] http://unstats.un.org/unsd/cr/registry/regcst.asp?Cl=231\&Lg=1, retrieved 2015-04-30

United Nations Statistics Division (2015b). The System of National Accounts (SNA) [online] http://unstats.un.org/unsd/nationalaccount/sna.asp Retrieved 2015-09-29

Urry, J. (2000) Sociology Beyond Societies: Mobilities for the Twenty First Century. London: Routledge

US Bureau of Labor Statistics (2012). American Time Use Survey User's Guide Understanding ATUS 2003 to 2011. [online] http://www.bls.gov/news.release/atus.nr0.htm retrieved 2013-03-15.

Wajcman J (2008). Life in the fast lane? Towards a sociology of technology and time. British Journal of Sociology, 59 (1)

Wallenborn \& Wilhite (2014). Rethinking embodied knowledge and household consumption Energy Research \& Social Science, 1 (56)

Ward, J.H., Jr. (1963). Hierarchical Grouping to Optimize an Objective Function, Journal of the American Statistical Association, 58

Whilborg, E. (2005). Flexible use of time to overcome constraints, IFIP International Federation for Information Processing, 178

Whilborg, E. \& Palm, J. (2008). Pockets of Local Orders for Local Policy Making - The Case of Information Society Infrastructure, European spatial research and policy, 15 (1)

Widén, J. (2010). System Studies and Simulations of Distributed Photovoltaics in Sweden. PhD dissertation, Uppsala University, Sweden

Widén, J. \& Wäckelgård, E. (2010). A high-resolution stochastic model of domestic activity patterns and electricity demand. Applied Energy, 87

Vilhelmson, B. (1999). Daily mobility and the use of time for different activities. The case of Sweden, GeoJournal, 48 (3)

Vilhelmson, B. The Use of the Car-Mobility Dependencies of Urban Everyday Life, In Garling, T and Steg, L. (eds) (2007). Threats from Car Traffic to the Quality of Urban Life: Problems, Causes, and Solutions, Oxford: Elsevier

Vrotsou, K. (2010) Everyday mining: Exploring sequences in event-based data. PhD dissertation, Linköping University, Sweden

Yanos, P., West, M., \& Smith, S. (2010). Coping, productive time use, and negative mood among adults with severe mental illness: A daily diary study. Schizophrenia Research, 124 

APPENDED PAPERS 


\section{Appended Papers}

The articles associated with this thesis have been removed for copyright reasons. For more details about these see:

http://urn.kb.se/resolve?urn=urn:nbn:se:liu:diva-122253 